\title{
LA EFICACIA DEL CORREO ELECTRÓNICO COMO MEDIO DE CONFIRMACIÓN EN EL PROCESO CIVIL Y COMERCIAL ${ }^{1}$
}

\author{
THE EFFECTIVENESS OF E-MAIL AS A MEANS OF CONFIRMATION IN THE CIVIL \\ AND COMMERCIAL PROCESS
}

Por Ángel Luís Ciappino ${ }^{(*)}$

\begin{abstract}
Resumen: La presente tesis abordara los sistemas informáticos, como las diversas comunicaciones electrónicas pueden ser insertadas en la faz probatoria del proceso civil, dando cumplimiento de los requisitos de admisibilidad, eficacia y validez. Se desarrollara la naturaleza tanto material como jurídica de los documentos electrónicos para poder determinar su contenido, los medios de comunicación, sus protocolos, programas, servidores, y realizar un análisis de sus componentes que nos permita prever la fuerza conviccional de los documentos electrónicos en especial el correos electrónicos dentro de los procesos judiciales, analizando los requisitos de existencia, validez y eficacia de los documentos con medios probatorios, para ello los jueces deberán analizar este medio probatorio Esta es una tarea sumamente compleja y difícilmente se pueda predicar con absoluta certeza sobre la fuerza conviccional de los correo electrónicos en los procesos, tal circunstancia deberá estar claramente fundada y justificada por las reglas de la sana crítica racional, pues como se explicara, los mecanismos de seguridad y conservación de la información de los documentos electrónicos son suficientemente sofisticados como para asegurar un nivel de confirmación elevado.
\end{abstract}

Palabras claves: Actos jurídicos - bases de datos - email - documentos jurídicos

\begin{abstract}
This thesis will deal with computer systems, how the various electronic communications can be inserted in the evidentiary face of civil proceedings, meeting the requirements of admissibility, effectiveness and validity. The material and legal nature of the electronic documents will be developed in order to determine their content, the means of communication, their protocols, programs, servers, and to carry out an analysis of their components that will allow us to foresee the convincing force of the electronic documents, especially the e-mails, within the judicial processes, analyzing the requirements of existence, validity and effectiveness of the documents with evidentiary means, This is an extremely complex task and it is difficult to predict with absolute certainty the strength of conviction of e-mails in the processes, such circumstance must be clearly founded and justified by the rules of sound rational criticism, because as explained, the mechanisms of security and conservation of information in electronic documents are sophisticated enough to ensure a high level of confirmation.
\end{abstract}

Keywords: Legal acts - data bases - email - legal documents

\footnotetext{
${ }^{1}$ Artículo recibido el 28 de julio de 2019 y aprobado para su publicación el 14 de octubre de 2019.

(*) Abogado (UNC). Escribano (US21). Profesor de Derecho Privado II (US21). Especialista en Derecho Procesal (UNC), Especialista en Derecho laboral (UNC), Diplomado en Derecho Civil por la Universidad Casilla la Mancha en Toledo, España, Diplomado en derechos y seguros y Diplomado en derecho a la salud (UNC)
} 


\section{(c) (i) $(5)$ \\ BY NC ND}

Artículo publicado bajo Licencia Creative Commons Atribución-No Comercial-Sin Derivar. (C) Universidad Católica de Córdoba

DOI http://dx.doi.org/10.22529/adc.2019(13)01 


\section{LA EFICACIA DEL CORREO ELECTRÓNICO COMO MEDIO DE CONFIRMACIÓN EN EL PROCESO CIVIL Y COMERCIAL}

\section{Introducción}

Los sistemas informáticos de toda índole son parte de la vida cotidiana moderna, las tecnologías de la información y la comunicación (TIC) se han convertido en el sistema nervioso de las sociedades contemporáneas y uno de los principales instrumentos utilizados es el correo electrónico. El e-mail es utilizado para toda clase de actos comunicacionales: cartas personales, mensajes profesionales, facturación de productos y servicios, publicidad comercial, y muchos otros posibles.

El fenómeno de la revolución informática imbuye todas las aristas de la vida en sociedad y genera múltiples cambios que afectan también a las relaciones jurídicas de las personas, marcando un progreso, pero también una crisis en la forma en que la tecnología afecta el goce de los derechos.

Sin embargo, la maleabilidad intrínseca de los objetos digitales siempre ha sido una fuente de duda sobre su legitimidad, ello ha provocado que la incorporación de las TIC a los procesos jurisdiccionales haya sido más lenta que en otros ámbitos. Esa precaución está justificada por la gravedad de los asuntos que se elucidan en los tribunales, pero negarlas completamente es tanto o más peligroso, por lo que paulatinamente han asentado su presencia.

Se ven avances en ámbitos tan diversos como la informatización de los procedimientos judiciales, en donde se han creado numerosos sistemas de gestión de causas y comunicación entre las partes de los procesos, así como la incorporación de la informática en un sentido más abstracto, siendo estos avances contemplados expresamente en las leyes, dando mayor legitimidad a los avances de la tecnología en el mundo jurídico.

Es en el marco de esa incorporación precavida de las nuevas tecnologías y su entendimiento como parte de la realidad jurídica de la sociedad, es que el correo electrónico ha encontrado un lugar como medio probatorio. Mas ese lugar no está perfectamente definido y aún existe un nivel de incertidumbre respecto de su capacidad como instrumento de prueba.

Esta duda se produce, tanto en relación a la posibilidad de entender a los e-mail como medios de prueba y en tal caso, a los hechos que ellos pueden probar. Como también, 


\section{LA EFICACIA DEL CORREO ELECTRÓNICO COMO MEDIO DE CONFIRMACIÓN EN EL PROCESO CIVIL Y COMERCIAL}

respecto a si estos constituyen hechos jurídicamente relevantes por sí mismos, o sólo existen en un universo virtual.

El objeto del presente será elucidar la eficacia confirmativa del correo electrónico presentado como prueba en el proceso civil. Para ello se ensayará su conceptualización como documento, es decir, como medio de confirmación, convicción, o acreditación; por lo que se presenta menester definir su naturaleza material y jurídica, y como ellas se insertan en el proceso civil en su faz probatoria.

En ese proceso, se intentará también profundizar en el funcionamiento de los correos electrónicos y de los documentos digitales en general, para entender la realidad que rodea a esos objetos jurídicos, y comprender mejor cómo es que se insertan en el sistema de Derecho ya existente.

A poco de pensar el asunto, surgen interrogantes que necesitarán respuesta para dar un análisis acabado del objeto a estudiar; en ese marco también trataremos de determinar el grado de confiabilidad del correo electrónico o si son necesarios medios de prueba complementarios para asentar la autenticidad de aquel. Las respuestas a estos cuestionamientos surgirán del análisis de la propia naturaleza del objeto y de cómo es percibido en los foros nacionales.

También pretendemos establecer cuáles son los parámetros exigidos por la doctrina o la jurisprudencia, para justificar la veracidad de la información que contienen, sobre quién los envía y cómo es que se reciben, todo ello para justificar su validez, pues si de hecho son admitidos como evidencia judicial, pues han de poseer aquellos requisitos necesarios para garantizar la veracidad de lo que demuestran.

Esos objetivos serán perseguidos aplicando un método analítico-descriptivo de doctrina autoral y jurisprudencial que permitirán establecer el marco en el que el objeto de estudio se encuentra, y especificar los requisitos de validez del correo electrónico como medio de prueba.

Cabe mencionar que la materia de estudio es de índole multidisciplinaria y transversal, por lo que se presenta necesario aclarar que se circunscribirá este estudio a una perspectiva jurídica, por lo que se deja al lector la profundización de exactitudes y pormenores que otras disciplinas tienen para proveer. Dentro del enfoque jurídico, se precisará aún más el 


\section{LA EFICACIA DEL CORREO ELECTRÓNICO COMO MEDIO DE CONFIRMACIÓN EN EL PROCESO CIVIL Y COMERCIAL}

objeto dentro del proceso civil y comercial, por lo que el impacto que se pudiera observar en otras ramas, tales como los procedimientos administrativos o penales, serán omitidos en este trabajo.

Ello no significa de ningún modo que el tema se agote en esos aspectos, sino que la posibilidad de extender el análisis de esta materia es tal que se requeriría de una extensión que supera con creces la de este trabajo.

Sin más cabe introducirse de lleno en el tema, iniciando con una breve conceptualización del objeto de estudio.

\section{$\underline{\text { El correo electrónico }}$}

\section{Comunicaciones electrónicas}

Para comenzar a hablar del correo electrónico es prudente empezar con una breve descripción de las comunicaciones electrónicas. Estas son el intercambio de mensajes e información realizada a través de computadoras conectadas entre sí por medio de una red informática.

Al hablar de computadoras vale hacer la aclaración de que se habla de cualquier tipo de sistema informático capaz de procesar y almacenar información, por lo que no se refiere exclusivamente a PC de escritorio, sino que se incluye a teléfonos celulares, computadoras portátiles, tablets, y otros tantos dispositivos que surgen constantemente a medida que la tecnología y las demandas del mercado avanzan.

Estas comunicaciones pueden darse entre dos computadoras sin intervención consiente del usuario, tales son, por ejemplo, los intercambios de información entre dos o más ordenadores necesarios para establecer una conexión a internet, esas comunicaciones se realizan automáticamente por medio de la aplicación de mecanismos como los protocolos TCP/IP (Transmission Control Protocol / Internet Protocol). Esta clase de comunicaciones no son de interés para este trabajo.

El desinterés no surge de su irrelevancia jurídica, pues la tiene, sino que, como ya se advirtió, la transversalidad de la informática en las relaciones jurídicas es tal que un estudio pormenorizado de cada faceta en un único trabajo resulta excesivo. 


\section{LA EFICACIA DEL CORREO ELECTRÓNICO COMO MEDIO DE CONFIRMACIÓN EN EL PROCESO CIVIL Y COMERCIAL}

Otra clase de comunicación es la que utilizan los usuarios para intercambiar mensajes entre sí, estas pueden ser sincrónicas o asincrónicas, ya sea que la conversación sea en tiempo real o no respectivamente. Dentro de las primeras se pueden mencionar los sistemas de chat o videoconferencia, dentro de las segundas se encuentran los foros, blogs, o los mismos correos electrónicos.

Por ejemplo, una video-llamada realizada por medio de un programa como el conocido Skype, se trata de un medio de comunicación sincrónica, pues la respuesta en la conversación se da de modo inmediato. Por otro lado, la publicación de un post en una red social como Facebook da lugar a una comunicación de tipo asincrónica.

Las comunicaciones electrónicas que se analizaran son aquellas asincrónicas que involucran el intercambio de mensajes entre dos o más usuarios, directa o indirectamente, y que se realizan utilizando software de e-mail. Por lo que también se excluyen aquellas comunicaciones entre usuarios que se realizan por medio de otros sistemas como chats, foros, o blogs.

\section{Los orígenes del e-mail}

Un elemento clave para la comprensión de todo fenómeno jurídico es el conocimiento, al menos somero, de los procesos que dieron origen a ese fenómeno. Por ello permítase una brevísima reseña histórica del correo electrónico, para poder comprender su génesis y su avance, y como termina encajando en la sociedad actual.

Ian Peter $^{2}$ afirma que el correo electrónico es más viejo que ARPANET o la internet, sus orígenes se remontan al uso de computadoras centrales y en las que un usuario guardaba un mensaje en un directorio al cual otro usuario podía acceder, tal como dejar una nota en el escritorio de un compañero de trabajo. Más adelante, y ya en la etapa de ARPANET los desarrollos de esta tecnología se aceleraron notablemente tal como relata "En 1972 también se introdujo la aplicación "hot" inicial, el correo electrónico. En marzo, Ray Tomlinson, de BBN, escribió el software básico de envío y lectura de mensajes de correo electrónico, motivado por la necesidad de los desarrolladores de ARPANET de un mecanismo sencillo de coordinación. En julio, Roberts amplió su utilidad escribiendo la primera utilidad de

2 Peter, I. (2004). NetHistory. Recuperado el 12 de Julio de 2015, de The history of email: http://www.nethistory.info/History\%20of\%20the\%20Internet/email.html

\begin{tabular}{llll}
\hline \hline ANUARIO DE DERECHO CIVIL & TOMO XIII & 2019 & Página 6
\end{tabular}




\section{LA EFICACIA DEL CORREO ELECTRÓNICO COMO MEDIO DE CONFIRMACIÓN EN EL PROCESO CIVIL Y COMERCIAL}

correo electrónico para hacer listas de mensajes, leerlos selectivamente, archivarlos, reenviarlos y responder a los mismos. A partir de ese momento, el correo electrónico se convirtió en la aplicación de red más importante durante más de una década. ”3.

Con el advenimiento de la World Wide Web y conexiones a internet económicamente accesibles los servicios de e-mail se popularizaron, especialmente con la aparición de servicios gratuitos ofrecidos por compañías como Yahoo o Microsoft (Hotmail), la facilidad de acceso aumentó la demanda de los servicios y los usuarios requerían al menos una dirección, y el medio fue adoptado por no sólo por millones, sino por cientos de millones de personas ${ }^{4}$. La importancia de esta herramienta ha crecido a tal punto que se proyecta que para el año 2016 el tráfico promedio de correos electrónicos enviados y recibidos ascenderá a veintitrés mil millones ${ }^{5}$.

Esas cifras indican claramente que la importancia de esta herramienta comunicacional no puede ser soslayada, y faltar en el correcto análisis de su peso jurídico implica un riesgo tanto para los derechos de los ciudadanos como para el apropiado cumplimiento de la función jurisdiccional.

\section{Funcionamiento del correo electrónico}

Para proveer a ese correcto estudio, es necesario entender, si no expertamente al menos tampoco sólo superficialmente, el funcionamiento de los sistemas de e-mail.

Téngase presente que los mecanismos que hacen posible las telecomunicaciones son de un elevado nivel técnico científico, por lo que se intentará describirlos del modo más llano posible, en atención a la necesidad de mantener la información focalizada en su faceta jurídica.

Los dos principales sistemas de uso del e-mail son a través de la utilización de programas clientes de correo (Outlook o Thunderbird son los más populares) y los servicios de webmail accesibles por los programas navegadores de internet, tales como Internet

\footnotetext{
${ }^{3}$ Leiner, B. M., Cerf, V. G., Clark, D. D., Kahn, R. E., Kleinrock, L., Lynch, D. C., . . . Wolff, S. (s.f.). Internet Society. Recuperado el 12 de Julio de 2015, de Breve Historia de Internet: http://www.internetsociety.org/es/breve-historia-de-internet

${ }^{4}$ Peter, I. op. cit.

5 The Radicati Group Inc. (2015). The Radicati Group. Recuperado el 12 de Julio de 2015, de Email Statistics Report, 2015-2019: http://www.radicati.com/wp/wp-content/uploads/2015/02/Email-Statistics-Report-20152019-Executive-Summary.pdf
} 


\section{LA EFICACIA DEL CORREO ELECTRÓNICO COMO MEDIO DE CONFIRMACIÓN EN EL PROCESO CIVIL Y COMERCIAL}

Explorer o Google Chrome (Hotmail y Gmail son los más usuales en esta categoría). Estas aplicaciones permiten la composición de mensajes de modo simple e intuitivo, sin embargo, en esa simplicidad se disipa el conocimiento de lo que sucede luego de presionar el botón "enviar".

Si bien puede aparentar una verdad evidente, es importante revisar los elementos estructurales que componen un e-mail, pues ellos también son relevantes para el funcionamiento de los mismos y para su eventual validez ante los tribunales.

Cada correo electrónico se compone de dos partes principales: el Encabezado (header en inglés) y el Cuerpo (body en inglés). Sobre el Encabezado se puede decir que es el equivalente a la información del sobre de una carta de papel y contiene información sobre el correo separada en campos: remitente, destinatario, asunto, fecha, etc., el Cuerpo es el propio contenido del mensaje que también puede contener un bloque con la firma del remitente ${ }^{6}$.

Una dirección de correo electrónico (remitente/s y destinatario/s) se compone de tres partes, en primer lugar el "nombre de usuario", en segundo lugar el nombre del computador en el que se encuentra alojada la cuenta de correo, y ambos separados por el símbolo “@” que en inglés se lee "at" (en), por lo que cada dirección se leerá como "usuario en computador". Eduardo Rodriguez Silvda, director del Grupo Chileno de Respuesta a Incidentes de Seguridad Computacional explica que

“(...) una vez que el usuario presiona el botón para enviar el mensaje, el correo se despachará siguiendo el siguiente procedimiento: El mensaje se transfiere al servidor de correo, que está asignado a la tarea de enviar estos mensajes.

El servidor de correo recibe la información del "sobre", es decir, destinatario del mensaje y remitente. Junto con ello, recibirá la información del "contenido del sobre" (el mensaje).

El servidor de correo identificará el servidor de correo que atiende al destinatario del mensaje o, en su defecto, a un intermediario

\footnotetext{
${ }^{6}$ Internet Engineering Task Force. (Octubre de 2008). Internet Engineering Task Force. (P. W. Resnick, Ed.) Recuperado el 13 de Julio de 2015, de RFC 5322 - Internet Message Format: https://tools.ietf.org/html/rfc5322
} 


\title{
LA EFICACIA DEL CORREO ELECTRÓNICO COMO MEDIO DE CONFIRMACIÓN EN EL PROCESO CIVIL Y COMERCIAL
}

\begin{abstract}
definido para tal efecto. Ambos, intermediario o destino final, son otros computadores, conectados a Internet, que actúan como servidores de correo en otras redes. Al completar el despacho, el mensaje será borrado del computador que lo envía.",
\end{abstract}

Tenga en cuenta el lector que el término servidor hace referencia a otras computadoras, que se distingue de los destinatarios y remitentes por la función que cumplen en el proceso de envío y reenvío de información, piénsese, en burda comparación, en los empleados de correo como los servidores de los correos tradicionales.

Aquella comunicación usualmente no se realiza directamente entre ambas computadoras, sino que el correo viaja por diversas maquinas llamadas "agentes de transferencia de mensajes" (ATM) (los servidores), enlazadas a internet por un proceso llamado “enrutamiento" que permite al tráfico de información encontrar el trayecto óptimo entre dos puntos de la red, según explica Daniel Altmark en su Tratado de Derecho Informático ${ }^{8}$

La comunicación es posible en base a procesos estandarizados denominados protocolos, el SMTP (simple mail transfer protocol) es el proceso más utilizado, aunque fue desarrollado pensando en la transferencia de mensajes entre maquinas conectadas permanentemente a la red, por lo que al aparecer computadoras personales con conexiones intermitentes fue necesaria una solución, pues los servidores no conservaban copias de los mensajes enviados.

Esa circunstancia dio origen al protocolo POP (Post Office Protocol) creado en 1984, que permite transferir a la computadora del usuario los mensajes alojados temporalmente en un servidor.

Originalmente los e-mail sólo permitían enviar mensajes en formato ASCII (caracteres de texto), lo que dio lugar al protocolo MIME (Multipurpose Internet Mail Extensions) en 1992, este estándar es el que se utiliza en la actualidad para enviar todo tipo de medios como imágenes, videos o sonidos.

\footnotetext{
${ }^{7}$ Rodriguez Silvda, E. (2003). Revista Chilena de Derecho Informático. Recuperado el 13 de Julio de 2015, de El Correo Electrónico:

http://www.derechoinformatico.uchile.cl/index.php/RCHDI/article/view/10668/11414

${ }^{8}$ Altmark, D. R., \& Molina Quiroga, E. (2012). Tratado de Derecho Informático (Vol. I). Buenos Aires: La Ley. págs. $780-781$ 


\section{LA EFICACIA DEL CORREO ELECTRÓNICO COMO MEDIO DE CONFIRMACIÓN EN EL PROCESO CIVIL Y COMERCIAL}

Con el POP3 (última versión del estándar POP) el usuario tiene el control físico de los archivos de correo, pues estos son alojados en su propia computadora personal. Para los servicios de webmail se utiliza el protocolo IMAP (Interactive Mail Access Protocol), cuya principal diferencia es que que los mensajes siempre quedan almacenados en el servidor ${ }^{9}$, por lo que son accesibles desde cualquier terminal con acceso a internet.

Como se ve, el sistema en general se presenta bastante intuitivo, un mensaje requiere ser enviado y pasa por distintos puntos hasta llegar a su destino. Lo importante es ver que ese destino puede no ser siempre la misma computadora, por lo que no siempre los destinatarios humanos se encuentran en completo control del soporte físico de los correos.

\section{Caracteres del correo electrónico}

Se verán ahora algunos de las características que presentan los correos electrónicos en su faz conceptual.

En la causa "PISANU JUAN MAURO C. CARTELUZ SRL. ORDINARIO. OTROS" la Cámara de Primera de Apelaciones en lo Civil y Comercial de la ciudad de Córdoba analiza la validez probatoria de los correos electrónicos, en unos de los apartados de los considerandos. Tras realizar una breve definición y descripción de los correos electrónicos y su funcionamiento elemental, el tribunal define ciertos caracteres comunes a los e-mail y que los tipifican: “a) es electrónico pues utiliza medios electrónicos de gestión y transporte de datos; b) es asíncrono: no necesita sincronía en envío y recepción; c) es ubicuo por cuanto permite su acceso en diferentes lugares; d) es digital por utilizar información digitalizada y e) es informático por cuanto está en relación con las tecnologías de información." ${ }^{\prime 10}$

\section{Electrónico}

Se refiere con este término a las herramientas que se requieren para la creación y administración de los documentos, se profundizará sobre este tema más adelante, pero cabe adelantar que el término "electrónico" es polisémico y no es comprensivo de todas las manifestaciones de TIC. Por lo que habrá de ser entendido en un sentido amplio en este caso.

${ }^{9}$ Ídem pág. 784

${ }^{10}$ PISANU JUAN MAURO C. CARTELUZ SRL. ORDINARIO. OTROS, 1642556/36 (Cámara de Primera de Apelaciones en lo Civil y Comercial de la Ciudad de Córdoba 22 de Mayo de 2014). 


\section{LA EFICACIA DEL CORREO ELECTRÓNICO COMO MEDIO DE CONFIRMACIÓN EN EL PROCESO CIVIL Y COMERCIAL}

\section{Asíncrono}

La mediación de diversos enrutadores entre el remitente y el destinatario de los correos, sumado a que los mismos quedan almacenados, ya sea en un servidor o en la propia computadora del destinatario, como se explicó ut supra, hacen posible las comunicaciones de modo no inmediato, lo que diferencia este medio de telecomunicación de otros como la telefonía, la radio, o los servicios de chat.

\section{Ubicuo}

Si bien es cierto lo que menciona el tribunal de que el acceso al correo electrónico es permitido desde diferentes lugares, cabe hacer la salvedad de que esto no es así para cualquier sistema de correo electrónico, sino que se refiere a los servicios de webmail o a aquellos servicios que utilicen el protocolo POP, o similares, con una función de sincronización de contenido con otros dispositivos.

Esto no presenta mayores dificultades conceptuales, pero puede poseer relevancia jurídica, pues la posibilidad de acceso a los correos implica una variación en los niveles de seguridad de los que goza la información, lo que luego pesará sobre la valoración que hará el tribunal de los documentos ofrecidos como prueba.

\section{Digital}

Este término se refiere a la forma en que la información es utilizada, la electrónica digital se enfoca en sistemas electrónicos que utilizan valores de tensión, corriente, etc, discretos, en contraposición a la electrónica analógica, que utiliza valores continuos de esas variables. Cabe destacar que los términos "electrónico" y "digital” no son unívocos, pues el primero se refiere a al soporte sobre el cual se opera el documento, que podrá ser electrónico, magnético, óptico, etc. Y el segundo se refiere a la forma en que la información del documento se encuentra codificada, en ceros y unos.

\section{Informático}

No sólo que está relacionado con las tecnologías de la información, el correo electrónico es uno de los frutos de la ciencia informática más relevantes de esta era. Lo que lo convierte en uno de los productos más paradigmáticos de esa ciencia.

De allí se deriva gran parte de su relevancia, pues como se explicó anteriormente, la explosión numérica y de complejidad que ha adquirido esta herramienta la convierte en una 


\section{LA EFICACIA DEL CORREO ELECTRÓNICO COMO MEDIO DE CONFIRMACIÓN EN EL PROCESO CIVIL Y COMERCIAL}

de las formas de comunicación más importantes tanto personal como profesionalmente de millones de personas alrededor del mundo.

\section{Documentos}

Se ha descripto y caracterizado a los correos electrónicos, sin embargo, en su dimensión jurídica, se los puede entender como una especie del género documento, más precisamente del subgénero documento electrónico. Ello conlleva a la necesidad de analizar estos géneros para también tener una visión del espacio conceptual en el que se enmarca el objeto analizado.

Se introducirá primero una visión general sobre las formas de los actos jurídicos, para que se pueda tener una mirada a la necesidad y utilidad que encuentran esos géneros en las relaciones de derecho.

\section{La forma de los actos jurídicos}

Desde antaño se ha visto la necesidad de registrar los actos jurídicos que realizan las personas, esto es indispensable para el mantenimiento de la seguridad jurídica, pues esos registros cumplen tanto la función de memoria como de evidencia de lo actuado.

La trascendencia de esas funciones ha impulsado el uso de las herramientas tecnológicas más avanzas, en cada época claro está, para confeccionar los objetos que almacenan la información, para proveer la mayor seguridad posible. Desde las antiguas tabletas de arcilla hasta las modernas tabletas electrónicas.

De los grandes cambios que acarrea la expansión e intensificación de las TIC, uno de los más relevantes, y tal vez preocupantes, para el mundo del Derecho es la introducción de una miríada de interacción jurídicamente relevantes que se realizan utilizando herramientas electrónicas, ya sea exclusivamente o coadyuvadas por ellas, y que se dan tan vertiginosa como cotidianamente. Ello acarrea una medida de incertidumbre respecto de la validez y existencia de los actos jurídicos.

Esto es así pues las herramientas utilizadas para llevar a cabo esos actos, si bien son comparables conceptualmente, son completamente diferentes funcionalmente a los medios utilizados hasta la irrupción de las TIC. Ello impuso la adaptación de la sociedad a gran escala a estas nuevas manifestaciones jurídicas. 


\section{LA EFICACIA DEL CORREO ELECTRÓNICO COMO MEDIO DE CONFIRMACIÓN EN EL PROCESO CIVIL Y COMERCIAL}

Por ejemplo, quien realiza una compra, no a través de un sitio dedicado a tal efecto, sino por una simple comunicación por e-mail, se somete a un importante grado de incertidumbre respecto de la existencia misma del contrato, más aún si no se han tomado ciertas medidas de seguridad para verificar las identidades de las partes o la certeza de las comunicaciones. Entonces, prescribir legalmente la observancia de solemnidades en situaciones similares se presenta como una forma tentadora de solucionar los potenciales conflictos.

Sin embargo, "Se ha señalado con todo acierto que el formalismo excesivo que impone la redacción de un escrito, en una época donde ya nadie escribe y donde generalmente una máquina se interpone entre el deudor y el acreedor, conduce a penalizar aquello que queremos proteger" ${ }^{\prime 1}$. La afirmación de que esta es una época en la que ya nadie escribe puede ser dudosa, pues gracias a los mensajes de textos, las redes sociales, y los propios correos electrónicos, gran parte de las comunicaciones humanas hoy se dan por escrito. Sin embargo, el espíritu de las palabras de Altmark quizás tome aún mayor importancia ante ese hecho, pues pretender imponer formalidades a lo que se ha convertido en una de las formas más comunes del uso del lenguaje se puede convertir en tan contraproducente como fútil.

Aquello que se quiere proteger, que mencionan Altmark y Molina Quiroga en el párrafo citado, es la fluidez y seguridad de los actos jurídicos, esas virtudes de la vida jurídica son de cardinal importancia para el sostenimiento del Estado de Derecho, pues hacen al ejercicio irrestricto de los derechos individuales.

El artículo 259 del C.C.C.N. define los actos jurídicos como " [...] el acto voluntario lícito que tiene por fin inmediato la adquisición, modificación o extinción de relaciones o situaciones jurídicas”. Y recuérdese que la validez o nulidad de esos actos depende de las leyes y usos del lugar en donde se celebren, según indica el artículo 2649 del mismo Código, esto es así pues es la forma la que visibiliza la manifestación de la voluntad necesaria.

Las formalidades, como se dijo, sirven para mantener la memoria fiel de lo actuado, por lo que también se erigen como medios de demostrar aquello en caso de existan cuestionamientos al respecto. Es por ello que la utilización de nuevas herramientas suele

${ }^{11}$ Altmark D. R. \& Molina Quiroga E. Op. Cit. pág. 522 


\section{LA EFICACIA DEL CORREO ELECTRÓNICO COMO MEDIO DE CONFIRMACIÓN EN EL PROCESO CIVIL Y COMERCIAL}

recibirse con suspicacia, pues los riesgos no son completamente conocidos, sin embargo, ello puede generar un estancamiento de los mecanismos jurídico-formales, y prevenir la actualización de las normas legales aplicables.

Afortunadamente, la última reforma al Código Veleziano ha venido a aliviar la norma de varias inconsistencias o divergencias conceptuales que causaban confusión al respecto de la exigencia de formalidades legales para la realización de actos jurídicos; acentuando el principio general de la libertad de formas, es decir, las partes de un negocio pueden decidir libremente, en principio, los requisitos exigidos.

Asimismo, se han incluido previsiones respecto de las particularidades de los documentos electrónicos. El artículo 286 del C.C.C.N. prevé que las expresiones escritas pueden "hacerse constar en cualquier soporte, siempre que su contenido sea representado con texto inteligible, aunque su lectura requiera medios técnicos". También, en su artículo 288 in fine, reitera la equiparación de la firma digital, haciendo una tácita remisión a la ley de Firma Digital 25.506. Más adelante se verá en más detalle en qué consiste esto.

Esa libertad de formas, en conjunto con el uso de herramientas informáticas se presentan de cardinal importancia, pues, más allá de que las formalidades no siempre se cumplan, existe una conciencia entre las partes de que las transacciones se han perfeccionado y han quedado documentadas, de algún modo, aunque no siempre quede claro cómo podría acreditarse el acto. Mayor relevancia adopta este asunto si se considera que la prueba documental es una de las más utilizadas al momento de demostrar las pretensiones en los tribunales.

Es por ello que la validez de los documentos electrónicos como prueba merece un análisis pormenorizado, lo que luego facilitará la comprensión de la validez del correo electrónico como tal.

\section{Los Documentos}

Los documentos, nos dicen Angelina F. de de la Rúa y Cristina de la Vega de Opl, son "[...] todo objeto, producto de un acto humano que represente a otro hecho o a un objeto, una persona o a una escena natural o humana[...] El documento se presenta como el vehículo que representa a ese pensamiento; el que puede formas. Así puede ser escrito o no escrito (por ejemplo intstrumentos públicos o privados y fotografías, planos, mojones, 


\section{LA EFICACIA DEL CORREO ELECTRÓNICO COMO MEDIO DE CONFIRMACIÓN EN EL PROCESO CIVIL Y COMERCIAL}

etcétera)." 12 . Es decir, los documentos son modos de retener la información de un acto o hecho que se necesita preservar, esa información es codificada en un código acordado (lenguaje escrito o simbólico) para que luego pueda recuperarse.

Es así que los documentos presentan dos dimensiones, en su dimensión extrínseca, el documento está conformado por una materia (papel, tela, etc.) capaz de ser moldeada para representar un hecho cualquiera. Altmark lo denomina "soporte" y al respecto afirma que "podemos incluir en este género a los soportes electrónicos y digitales, que son elementos que permiten almacenar la información para su tratamiento y recuperación"13. Se trata del sustrato material sobre el que se asienta el símbolo capaz de transmitir información.

Desde su dimensión intrínseca, el documento contiene la representación del hecho que registra, trae ante el juez el hecho ausente que se ha codificado en él, y que es decodificado por un acto intelectivo. Es el contenido de información, codificada, lo que permite relatar fielmente, en el presente, lo acontecido en el pasado.

Altamark, citando a Juan Colerio, explica que

"la concepción jurídica tradicional ha extendido la noción "expresión por escrito" a todo el ámbito del documento, extralimitando un requisito de la especie (instrumento) a todo el género (documento), a pesar de que existan otros medio, que sin ser escritos, cumplen la función documental, es decir, que registran y conservan hechos y circunstancias de la vida real y negocial, tales como las fotografías, las películas cinematográficas, los microfilms, los discos o cintas fonográficas,

Por lo tanto, no es imprescindible que la información se almacene en un lenguaje escrito, en tanto se presente de un modo inteligible pues de otro modo se traicionaría el propósito del documento.

\footnotetext{
${ }^{12}$ Ferreyra de de la Rúa, A., \& Gonzáles de la Vega de Opl, C. (2002). Código Procesal Civil y Comercial de la Provincia de Córdoba, Comentado y Concordado con los Códigos de la Nación y Provinciales (Vol. 2). Buenos Aires: La Ley. pág. 428

${ }^{13}$ Altmark D. R. \& Molina Quiroga E. Op. Cit. pág. 526

${ }^{14}$ Ídem pág. 527
} 


\section{LA EFICACIA DEL CORREO ELECTRÓNICO COMO MEDIO DE CONFIRMACIÓN EN EL PROCESO CIVIL Y COMERCIAL}

Alvarado Velloso ${ }^{15}$ profundiza sobre el tema, haciendo un análisis pormenorizado de las diferentes manifestaciones que pueden adoptar las pruebas documentales en sentido amplio. En su estudio, las clasifica en cuatro tipos, Instrumentos, Documentos, Monumentos, y Registros:

\section{Instrumentos}

Son los medios de acreditación que plasman original e indubitablemente las relaciones jurídicas, se presentan siempre en forma escrita y, por definición, son siempre auténticos. Están estrechamente ligados a la fe pública, y en la terminología tradicional incluye a los documentos públicos o, cuando se dan ciertos requisitos, los documentos privados.

Tenga el lector presente esta clase, pues más adelante se verá cómo la posibilidad de revestir esa certeza jurídica modifica la forma en que un documento es percibido por los tribunales al momento de ser valorado como elemento probatorio.

\section{Documentos}

También son medios que representan por escrito la materialización de un pensamiento o circunstancia, pero, a diferencia del instrumento, estos no son fehacientes por lo que son siempre privados e inauténticos, por ende, no creíbles prima facie, pues su credibilidad estará condicionada por la eventual confirmación por la persona contra quien se opone.

Esto no les priva de toda fuerza probatoria, sino que los documentos, entendidos en este sentido estricto, no pueden sostenerse por sí mismos para demostrar un hecho jurídicamente relevante, y han de ser coadyuvados de otros esfuerzos probatorios para alcanzar el convencimiento del juzgador.

\section{Monumento}

En estos, los hechos o pensamientos se materializan mediante formas o figuras a las que, por ley o convención, se les otorga significado. Piénsese en alambrados, cercas, diagramas, signos, marcas de ganado, señales de tránsito, etc.

Es de notar que los monumentos suelen ser no escritos, lo que los distingue de los medios ya mencionados, pero ello no obsta a que transmitan información de importancia jurídica.

$$
\text { Registro }
$$

\footnotetext{
15 Alvarado Velloso, A., \& Gonzalez Castro, M. A. (2012). Lecciones de Derecho Procesal Civil. Rosario: Fundación para el Desarrollo de las Ciencias Jurídicas.
}

\begin{tabular}{llll}
\hline \hline ANUARIO DE DERECHO CIVIL & TOMO XIII & 2019 & Página 16
\end{tabular}




\section{LA EFICACIA DEL CORREO ELECTRÓNICO COMO MEDIO DE CONFIRMACIÓN EN EL PROCESO CIVIL Y COMERCIAL}

"Es el medio de acreditación por el cual se captan técnicamente expresiones del hombre o de la naturaleza en general y las apariencias mismas de las cosas, cuya materialización se hace de forma tal que puede ser perdurable o utilizable y reproducible a voluntad" 16.

Se refiere a grabaciones y discos, electrocardiogramas, negativos fotográficos y fílmicos, registros de voces y sonidos, de fotoquímica, copias en general, etc. No ostentan lenguaje escrito ni están conformados por formas o figuras, por lo que no pueden ser considerados ni documentos o instrumentos ni monumentos. Es decir que no poseen una descripción de los hechos, ni comunican a través de símbolos abstractos, sino que almacenan una copia del propio hecho u objeto que se quiere conservar.

Vale aclarar entonces que el término documento puede ser entendido en sentido amplio, para abarcar todos los medios de prueba documental, o en sentido estricto para referirse específicamente al medio escrito, privado y no fehaciente.

\section{Requisitos de los documentos}

Sin perjuicio de la pormenorización realizada, pueden mencionarse requisitos comunes de los documentos entendidos en sentido amplio, es decir que estos se exigen de los instrumentos, documentos, monumentos, y registros por igual. Estos requisitos son los de inalterabilidad, autenticidad, y durabilidad, que se pasa a explicar a continuación:

\section{Inalterabilidad}

Se exige de los documentos que mantengan de manera permanente su contenido, es decir que la información que registran ha de ser inmutable en la mayor medida posible, pues la posibilidad de la modificación merma la confiabilidad que se espera de un medio probatorio.

En este sentido, los documentos electrónicos se presentan particularmente vulnerables, pues la propia accesibilidad en la que se asientan las TIC provoca que la mutabilidad de los archivos electrónicos sea muy alta.

Es por ello que suelen requerirse otras formas de validar el contenido de los e-mail, ya sea por medio de un reconocimiento de los mismos o una prueba pericial que verifique si han sido alterados o no, y en su caso en que medida.

\section{Autenticidad}

16 Ídem. Pág 564 


\section{LA EFICACIA DEL CORREO ELECTRÓNICO COMO MEDIO DE CONFIRMACIÓN EN EL PROCESO CIVIL Y COMERCIAL}

Un documento será auténtico cuando no haya sufrido cambios en su contenido, por lo que este requisito se presenta como la contracara de la inalterabilidad. Un documento ofrecerá mayor seguridad cuanto más difícil sea alterarlo, y, llegado el caso, cuanto más sencillo sea verificar su alteración y reconstruir su contenido original.

Nuevamente, este es una cuestión ríspida para los archivos informáticos, pues su modificación es sumamente sencilla. Sin embargo, la enorme capacidad de almacenamiento de información de los ordenadores modernos hace más sencillo conservar el rastro de modificaciones, por lo que robustece la faz de reconstrucción de los contenidos originales.

Esto se patentiza en los historiales de cambios de los archivos, registros de versiones, fechas de modificación, y registros de esas modificaciones. Además, las memorias físicas, aún cuando se han eliminado los archivos, pueden conservar rastros de la información almacenada, y que por medios técnicos más sofisticados puede recuperarse.

\section{Durabilidad}

Este requisito se refiere a la condición de indeleble del contenido, es decir, a la imposibilidad de destruirlo o modificarlo sin destruir o modificar el soporte en el que se encuentra. En este aspecto los documentos electrónicos son particularmente susceptibles, pues si bien, al simplemente eliminar un archivo no toda la información queda perdida irremediablemente, existen medios relativamente accesibles para conseguir la destrucción de la información sin destruir dispositivos de almacenamiento.

Sin embargo, se han desarrollado métodos de conservación de la información que permiten la protección de los datos y de sus soportes, algunos de estos medios se analizaran más adelante.

\section{El Documento Electrónico}

Cabe hacer algunas precisiones técnicas respecto de lo que entiende cuando se menciona el documento electrónico. Estos son documentos (en sentido amplio) realizados con el uso de una computadora, más específicamente, es aquel documento que ha sido confeccionado con intervención humana. Si bien existe la posibilidad de que se generen documentos automáticamente, estos no son de interés para el presente trabajo. 


\section{LA EFICACIA DEL CORREO ELECTRÓNICO COMO MEDIO DE CONFIRMACIÓN EN EL PROCESO CIVIL Y COMERCIAL}

Dentro de esa definición se pueden descubrir dos categorías, una es el documento electrónico en sentido amplio, y las otra el documento electrónico en sentido estricto.

Por documento electrónico en sentido amplio se entiende a aquel que es comprensible en lenguaje natural sin necesidad de maquinas que traduzcan las señales electromagnéticas. Son aquellos que se han formado a través de los "órganos de salida" del ordenador y es perceptible por el hombre por sus propios sentidos ${ }^{17}$.

Al referirse "órganos de salida", los autores hablan de los dispositivos periféricos de salida de las computadoras, estos son más comúnmente los monitores e impresoras, también se pueden incluir a los altavoces o auriculares para documentos acústicos, o inclusive las impresoras 3D, para objetos corpóreos.

En sentido estricto, son aquellos fijados en soporte electrónico u óptico de información, son los que quedan registrados en la memoria de la computadora, y se incluye en el concepto aquellos medios de hardware y software necesarios para su recuperación. Estos son los que usualmente representan el modelo paradigmático de documento electrónico.

\section{El e-mail como documento}

En este esquema, los correos electrónicos pueden ser documentos (electrónicos), en sentidos estricto y amplio, o instrumentos, si logran reunir los requisitos para dar certeza de su contenido -lo que es técnicamente posible aunque de difícil realización- también pueden tener característica de monumento o de registro, según el formato que posea su contenido que, como ya se explicó anteriormente, puede adoptar múltiples tipos.

Cabe hacer la salvedad que el contenido de los e-mails, desde un punto de vista ontológico, poseen una doble capa de codificación. Una primera capa se da, por ejemplo, a nivel lingüístico, en el que el hecho comunicacional que representa se encuentra registrado en algún lenguaje humano o humanamente comprensible (textos, imágenes, etc.). La segunda capa se halla en su codificación digital, en lenguaje de computadora, por medio del cual es transmitido a través de la red.

Además, es menester tener presente que el correo electrónico puede ser de un tipo y contener, como adjunto, un archivo que se yerga en otro tipo de medio de acreditación. Por

${ }^{17}$ Altmark D. R. \& Molina Quiroga E. Op. Cit. pág. 246 


\section{LA EFICACIA DEL CORREO ELECTRÓNICO COMO MEDIO DE CONFIRMACIÓN EN EL PROCESO CIVIL Y COMERCIAL}

ejemplo, un correo electrónico simple, que sólo sirva como documento, puede transmitir un archivo que posea los requisitos necesarios para ser un instrumento, como puede ser un documento con firma digital equiparada a la firma manuscrita.

Esos niveles de anidamiento de información provoca un aumento de la complejidad en la valoración del correo electrónico como prueba en un proceso judicial, pues la falencia de certeza en alguno de sus niveles puede causar, por transitividad, la falencia de certeza en los subsiguientes, requiriendo entonces un mayor control de veracidad del elemento, lo que se complejiza aún más dada la naturaleza eminentemente técnica del correo electrónico.

Sin embargo, esa complejidad no es óbice para su aceptación en un proceso judicial, tal como lo tiene dicho la jurisprudencia: "resulta viable ofrecer correos electrónicos como prueba en el proceso judicial en función del principio de libertad de medios expresamente consagrado en la ley del rito local (art. 202 C.P.C.), cabe precisar que su valoración se encuentra sujeta en primer lugar a que pueda comprobarse su autenticidad"18. La única salvedad es la posibilidad de verificar la veracidad de la autoría y el contenido del correo electrónico, lo que también puede relativizarse, ya sea porque el correo electrónico en sí mismo (no su autor ni su contenido) es el hecho que se desea probar, o porque verificada la autoría el contenido resulta irrelevante o viceversa. Se verán algunos ejemplos de esto al momento de analizar casos jurisprudenciales.

Respecto de los requisitos de inalterabilidad, autenticidad, y durabilidad, los correos electrónicos adolecen de los mismos problemas, y gozan de las mismas virtudes, que otros documentos electrónicos. Aunque en general la adulteración de estos es más compleja, pues en muchos casos los archivos no están directamente disponibles para su edición por parte del usuario, que sólo puede verlos.

Como se mencionó, existen medios para proteger la información en los documentos electrónicos, a continuación se estudiarán algunos de los más importantes.

\footnotetext{
${ }^{18}$ PISANU JUAN MAURO C. CARTELUZ SRL. ORDINARIO. OTROS, 1642556/36 (Cámara de Primera de Apelaciones en lo Civil y Comercial de la Ciudad de Córdoba 22 de Mayo de 2014).
}

\begin{tabular}{llcr}
\hline \hline ANUARIO DE DERECHO CIVIL & TOMO XIII & 2019 & Página 20
\end{tabular}




\section{LA EFICACIA DEL CORREO ELECTRÓNICO COMO MEDIO DE CONFIRMACIÓN EN EL PROCESO CIVIL Y COMERCIAL}

\section{Firma Digital}

Se ha hecho mención a la firma digital anteriormente y se ha acentuado la necesidad de utilizar algún método de verificación de los correos electrónicos para poder ser utilizados como elementos probatorios.

Sin embargo, antes de poder adentrarse de lleno en el estudio de la firma digital, su validez y recepción en el ordenamiento jurídico argentino, es menester primero tratar el tema de la seguridad de la información, que si bien es una disciplina de la informática en sí misma, tendrá que bastar con una reseña atento a la longitud del presente trabajo.

\section{Seguridad de la información}

La cuestión de la seguridad de los mensajes, la garantía de su recepción y la integridad de su contenido, no es algo nuevo. Métodos de encriptación se usan desde antaño, y mensajeros y correos han sido personajes de gran importancia en todas las sociedades, antiguas y modernas.

Los diversos modos de proteger los mensajes tales como códigos, lacres o llaves, son necesarios para poder garantizar los requisitos de los documentos para que así estos puedan cumplir con sus funciones de seguridad jurídica y certeza de los negocios.

El cumplimiento de los requisitos de los documentos depende de la seguridad que envuelva

al proceso de creación y emisión del documento. Los progresos en esos aspectos es constante y las técnicas de seguridad basadas en biometría y otras técnicas criptográficas han venido a hacer las veces de sellos de lacre en las modernas vías de comunicación.

Sin embargo se dice que la seguridad informática es un proceso constante, pues a medida que los métodos de seguridad avanzan, también lo hacen los métodos para violar esa seguridad. Es una carrera inacabable en la que gana quien logre evolucionar más rápido.

Esa evolución permanente ha logrado que se permita la verificación de la autoría atribuida en la emisión, como la inalterabilidad del contenido del documento, en forma tanto o más convincente que un instrumento firmado con una firma ológrafa.

Ello es así pues la importancia y volumen de los negocios jurídicos realizados por medios electrónicos han adquirido tal trascendencia que se han invertido enormes recursos en investigación en el área de la seguridad informática. A tal punto que hoy por hoy, los 


\section{LA EFICACIA DEL CORREO ELECTRÓNICO COMO MEDIO DE CONFIRMACIÓN EN EL PROCESO CIVIL Y COMERCIAL}

documentos electrónicos pueden poseer mayores y mejores niveles de seguridad que un documento de otro tipo.

\section{Criptografía}

La criptografía es un método que consiste en la ofuscación de la información mediante el uso de claves, modernamente esas claves consisten en complejos algoritmos matemáticos que hacen imposible la comprensión de la información por parte de alguien que no conozca el sistema y que posea los recursos computacionales suficientes para operar los incontables cálculos necesarios para decodificar un mensaje.

Encriptar significa modificar los caracteres de un texto de tal modo que el mismo no pueda comprenderse sin un proceso de desencriptación. Por ese proceso no sólo se logra develar el contenido del texto enviado, sino que también se logra verificar la identidad del remitente del mensaje. Esto es así pues, por medio de los algoritmos referidos, se ata la identidad del autor a la posibilidad de desencriptar la información, de ese modo al lograr esto último, se confirma lo primero.

Existen diversos sistemas de encriptación, los sistemas convencionales o simétricos, se valen de una clave única, que funciona tanto para cifrar como para descifrar el texto. Un ejemplo ubicuo es el del PIN o contraseña que se utiliza en los cajeros automáticos ${ }^{19}$.

Este sistema tiene la ventaja de su simplicidad, pero adolece de riesgos de seguridad evidentes, el sólo hecho de descubrir la clave hace que cualquier persona pueda hacerse pasar por el usuario legítimo o acceder a la información que se pretendía resguardar.

Distinta de la firma tradicional, este sistema lleva la clave antes de la declaración que se haga, por lo que repudiar el contenido también implica el desconocimiento de la clave ingresada.

Otro sistema, orientado a solucionar los problemas de la criptografía convencional es el llamado criptografía asimétrica o de clave pública, este sistema se vale de dos claves complementarias, una pública y la otra privada. Los usuarios generan su propio par mediante el uso de un software de confianza que garantiza que ningún usuario puede recibir el mismo par de claves accidentalmente.

${ }^{19}$ Altmark D. R. \& Molina Quiroga E. Op. Cit. pág. 573 


\section{LA EFICACIA DEL CORREO ELECTRÓNICO COMO MEDIO DE CONFIRMACIÓN EN EL PROCESO CIVIL Y COMERCIAL}

La clave pública puede ser conocida por cualquier persona, y para garantizar que una determinada clave pública pertenece a una determinada personal se acude a organizaciones de confianza que certifican esa identidad.

Como se percibe, existen varios niveles en los que la confianza en algún eslabón de la cadena de seguridad es indispensable, en esos aspectos es de trascendental importancia la concurrencia de mecanismos confiables y eficaces de control, para aumentar las garantías de fiabilidad.

El sistema de clave pública permite que cualquier persona cifre un mensaje con la clave pública del destinatario, garantizando la confidencialidad de la comunicación, pues sólo este puede decodificar el mensaje utilizando su clave privada. Por otro lado, si es el usuario quien codifica el mensaje con su clave privada, el destinatario (usando la clave pública) tendrá garantizada la identidad y autenticación del remitente, pues sólo aquel pudo enviar el mensaje utilizando su clave privada.

Este es el sistema que subyace a la llamada firma electrónica y que, se adelanta, es el utilizado por la legislación argentina para presumir la validez de los documentos así enviados.

El lector podrá notar que la clave es la piedra angular en la que se asienta todo el sistema de seguridad. Ello conlleva la necesidad de asegurar claves lo suficientemente complejas para crear una gran dificultad para conocerlas, sin embargo, la mayor complejidad de claves alfanuméricas trae aparejada el problema de que los usuarios no las recuerden y tengan que anotarlas, lo que significa un riesgo de seguridad.

Es por ello que han surgido diversos medios para garantizar aquella dificultad de acceso sin el problema de la dificultad de memoria. Uno de esos medios son los sistemas biométricos que se analizan a continuación.

\section{Biometría}

La biometría usa datos corporales de las personas para identificarlas ya que algunos aspectos corporales varían entre cada individuo, tales como las huellas dactilares, el iris de los ojos, o la estructura facial. 


\section{LA EFICACIA DEL CORREO ELECTRÓNICO COMO MEDIO DE CONFIRMACIÓN EN EL PROCESO CIVIL Y COMERCIAL}

De esta forma, el usuario no tiene que conocer una combinación de letras y números, sino que sólo utiliza su cuerpo como forma de conseguir una clave aleatoria pero permanente y de fácil acceso para él.

En informática se aplican técnicas de medición de esas estructuras físicas, directa o indirectamente para la utilización de esos datos en la verificación de la identidad de los usuarios. Así, el instrumento medidor es capaz de generar el código de acceso con base en la forma del cuerpo.

Las técnicas biométricas pueden ser estáticas, si se enfocan en analizar la anatomía del usuario (manos, huellas dactilares, iris, retina, etc.), o dinámica, si mide el comportamiento de la persona (patrón de voz, firma manuscrita, dinámica del tecleo, etc). Según sea el caso, cada técnica provee de distintos niveles de certidumbre y seguridad, aunque estas áreas están en constante cambio, por lo que no se puede afirmar definitivamente que alguna sea absolutamente mejor que otras.

Para que estas técnicas puedan ser utilizadas con mayor seguridad, deben basarse en elementos que sean certeramente diversos entre personas, los rasgos físicos varían entre los individuos, pero poder asegurar la unicidad de los elementos identificatorios significa asegurar la no confundibilidad entre distintas personas.

Otra cuestión necesaria es la relativa facilidad para ser detectados por las máquinas, pues al depender enteramente en la medición mecánica de los rasgos, el error en esa medición puede involucrar el error en todo el sistema.

Además, los rasgos a identificar no deben variar a lo largo de vida de las personas, ya sea por envejecimiento o enfermedad, para poder asegurar la individualización a lo largo del tiempo.

Finalmente, esas técnicas deben ser aceptables para el usuario, por lo que no deben ser invasivos o demasiado indiscretos, pues de nada serviría un sistema que cumpla idealmente con todos los otros requisitos si los individuos destinatarios del sistema no están dispuestos a usarlos.

Si bien la biometría, en combinación con otras medidas de seguridad como la criptografía asimétrica, es sumamente prometedora como método identificatorio, también, y por las mismas razones, trae aparejados potenciales problemas de invasión de la esfera de 


\section{LA EFICACIA DEL CORREO ELECTRÓNICO COMO MEDIO DE CONFIRMACIÓN EN EL PROCESO CIVIL Y COMERCIAL}

privacidad de las personas, por lo que puede tornarse en un problema más grande del que promete solucionar.

Esto es así porque permite el control, del manejo de información personal y del acceso a los bienes y servicios informatizados, a través de la utilización de mecanismos automáticos, lo que otorga una fuerte injerencia en la vida privada de los usuarios a quienes controlen esos sistemas.

Sin olvidarlos, pero más allá de todo cuestionamiento, resulta indudable que la seguridad informática provee suficientes elementos para garantizar adecuadamente la completitud, integridad e inalterabilidad de los contenidos de los documentos, y la declaración de voluntad que ellos puedan revestir, así como la identidad del emisor de ellos.

Desafortunadamente un sistema perfecto es prácticamente imposible de alcanzar, sin embargo nunca los sistemas para proteger la información lo han sido, sin que ello paralice la vida negocial y jurídica de las personas.

\section{Infraestructura de clave pública PKI}

El modelo más esparcido globalmente de criptografía de clave pública es el conocido como RSA (por las iniciales de sus creadores Rivest, Shamdir y Adleman), con un software basado en este sistema se puede generar la clave privada que consiste en un número largo que se almacena en la computadora.

La base del cifrado se asienta sobre el producto de números primos enormes, y para el descifrado se utilizan esos números en sí mismos. La cantidad y complejidad de los cálculos para romper el código es tan grande que el tiempo computacional requerido hace virtualmente imposible, y en la práctica inútil, intentarlo.

Por medio de una función matemática, conocida como función hash, se calcula un código que es único para el documento y que se envía adjunto al mensaje. Esa huella o marca es única para cada documento y sólo puede ser producida por quien poseía la clave privada. Utilizando la clave pública, esa función se generará nuevamente, lo que se compara con la enviada adjunta al mensaje, al coincidir confirman que el remitente es quien dice ser y que el mensaje no ha sido adulterado de ningún modo.

Por supuesto todos estos procesos y cálculos son realizados por computadoras, de allí la aclaración que se hizo previamente de la necesidad de utilizar un software de confianza. 


\section{LA EFICACIA DEL CORREO ELECTRÓNICO COMO MEDIO DE CONFIRMACIÓN EN EL PROCESO CIVIL Y COMERCIAL}

Otro elemento de seguridad que posee este sistema es que las claves pública y privada, si bien están relacionadas entre sí, no pueden derivarse una de la otra, ni tampoco a partir de los documentos cifrados por ellas.

Esto significa que no importa que tan poderoso sea el sistema informático del atacante, no podrá deducir una clave utilizando la otra, por lo que deberá recurrir a medios más complejos o riesgosos para obtener sus objetivos, lo que sirve como modo de disuasión.

Para poder controlar que el firmante es quien dice ser, se utilizan certificados digitales. Escencialmente estos certificados son el medio que se posee para confirmar que el titular de una clave es una determinada persona, y son emitidos por entidades autorizadas.

En la generación de estos certificados intervienen terceros de confianza usualmente conocidos como entidades (o autoridades) certificantes, y otras que se conocen como autoridades u operadores de registro, que verifican la identidad del firmante titular del certificado. Este sistema, informático y burocrático, se conoce como Infraestructura de Clave Pública o PKI (Public Key Infraestructure).

La PKI es un conjunto que incluye leyes, normativa legal complementaria, obligaciones, hardware, software, bases de datos, estándares tecnológicos y procedimientos de seguridad. En Argentina también se la denomina "Infraestructura de Firma Digital".

\section{La firma digital en la ley 25.506}

La ley 25.506 vino a reconocer los documentos y firmas electrónicas o digitales, reconociéndoles eficacia jurídica y otorgando una mayor seguridad jurídica a los negocios realizados con el uso de las TIC.

Esta norma equipara la firma digital, con los requisitos que exige, a la firma ológrafa, dando idéntica validez legal a los documentos electrónicos que la posean. Además reconoce, aunque con menor fuerza probatoria, a la denominada firma electrónica, que es la identificación electrónica que no posee todos los requisitos de la firma digital.

Según la ley "Se entiende por firma digital al resultado de aplicar a un documento digital un procedimiento matemático que requiere información de exclusivo conocimiento del firmante, encontrándose ésta bajo su absoluto control. La firma digital debe ser susceptible de verificación por terceras partes, tal que dicha verificación simultáneamente permita 


\section{LA EFICACIA DEL CORREO ELECTRÓNICO COMO MEDIO DE CONFIRMACIÓN EN EL PROCESO CIVIL Y COMERCIAL}

identificar al firmante y detectar cualquier alteración del documento digital posterior a su firma". Como se puede observar, la ley hace una referencia general a la infraestructura PKI. Aclarando, firma electrónica será el conjunto de dato electrónicos ligados de manera lógica a otros datos y que sirvan como medio de identificación del signatario, pero que carece de alguno de los requisitos para la firma digital.

Al respecto, Luz Clara afirma que "la base tecnológica para otorgarles validez jurídica estará dada por el establecimiento de la infraestructura de firma digital que ofrece autenticación y garantía de integridad de los documentos digitales y/o electrónicos"20.

Teniendo en cuenta lo dicho, se puede afirmar que la legislación vigente al respecto de la firma, electrónica o digital, le otorga plena validez jurídica a ambas, con la sola diferencia de que otorga una presunción de veracidad a la firma digital, operando una inversión de la carga de la prueba sobre quien la impugne. A la inversa, la responsabilidad de probar la validez de la firma electrónica queda en manos del signatario.

Esto es de cardinal importancia, pues al momento de presentar un documento electrónico, en el caso de este trabajo será un e-mail, como prueba en un proceso judicial, ante la impugnación del mismo, quien cuente con una firma digital se verá beneficiado con una presunción a su favor que, como se ha visto, es de dificultosa prueba en contrario.

Ahora bien, los requisitos legales para conformar la firma digital son definidos en el artículo 9 de la norma bajo análisis, que exige de la firma:

a) Haber sido creada durante el período de vigencia del certificado digital válido del firmante.

Este apartado hace referencia a la necesidad de proteger la confianza que se tiene sobre el certificado emitido por el ente certificador. De esta manera se hace necesaria una actualización periódica de los certificados.

b) Ser debidamente verificada por la referencia a los datos de verificación de firma digital indicados en dicho certificado según el procedimiento de verificación correspondiente.

Esencialmente este inciso hace referencia al proceso lógico matemático que deben cumplir los datos a verificar,

${ }^{20}$ Luz Clara, B. (2006). Ley de Firma digital comentada. Buenos Aires: Nova Tesis. Pág 30 


\section{LA EFICACIA DEL CORREO ELECTRÓNICO COMO MEDIO DE CONFIRMACIÓN EN EL PROCESO CIVIL Y COMERCIAL}

c) Que dicho certificado haya sido emitido o reconocido, según el artículo 16 de la presente, por un certificador licenciado.

El artículo 16 habla de los requisitos para reconocer a entes certificadores extranjeros. Este inciso, en paralelo al inciso a) se basa en la necesidad de asegurar la confianza en la infraestructura de firma digital, en este caso en la confianza a los entes certificadores.

La norma hace extensiva la validez de la firma digital a todas las instancias jurídicas en las que la ley exige firma manuscrita, equiparando ambas en cuanto a su valor legal. No es otra cosa que extender el concepto tradicional de firma para incluir a la firma digital ${ }^{21}$.

Cabe hacer una aclaración al respecto de cómo la ley 25.506 trata a las firmas digital y electrónica, respectivamente. El texto de la norma parece implicar que sólo la firma digital goza de la equiparación de con la firma manuscrita y que es sólo esta la que puede servir como método de verificación de la identidad del suscribiente. Sin embargo, una interpretación sistémica de la norma debe indicar que ambas formas tienen la misma validez en cuanto a su valor jurídico, con la sola diferencia, ya mencionada, de la presunción de carácter procesal probatorio que se le otorga a la firma digital.

\section{Presunción de autoría}

Esta presunción contenida en el artículo 7 de la norma estudiada, implica que un documento firmado digitalmente será considerado válido y dado por su autor según sea identificado por la firma digital, y por ello, si alguien invoca la falsedad de dicha identidad, caerá cobre el acusador la carga de la prueba.

\section{Presunción de integridad}

Como se ha dicho, una de los requisitos esenciales de los documentos electrónicos es el de la integridad del mismo, es decir, que se debe poder verificar que la declaración de voluntad recibida no ha sido modificada de su original, creado por el autor del mismo.

En el artículo 8, la ley 25.506 establece la presunción iuris tantum de que el documento firmado digitalmente, y que resiste el procedimiento de verificación, no ha sido modificado en forma alguna desde su firma.

\footnotetext{
${ }^{21}$ Altmark D. R. \& Molina Quiroga E. Op. Cit. pág. 591
} 


\section{LA EFICACIA DEL CORREO ELECTRÓNICO COMO MEDIO DE CONFIRMACIÓN EN EL PROCESO CIVIL Y COMERCIAL}

Esto en función a lo que se explicó sobre el procedimiento lógico-matemático de verificación, pues el contenido y la identidad del autor están unidos al ser necesario para la decodificación del mensaje la clave pública del autor.

No repudio

Las presunciones vistas constituyen lo que se denomina garantía de no repudio, es decir que otorgan eficacia probatoria al documento firmado digitalmente en los términos de esas presunciones.

Ello parecería indicar que existe una forma sencilla de dar fe de los documentos electrónicos de un modo que se pueda sostener fuertemente ante un examen jurisdiccional. Sin embargo, se ha optado por un sistema que requiere de entidades certificantes para emitir los certificados digitales necesarios, y esas entidades deben obtener a su vez una licencia por parte de la autoridad de aplicación.

Esa opción no es caprichosa ni banal, pero en cierta medida responde a una desconfianza generalizada subyacente en los sistemas informáticos, por lo que se erigen barreras burocráticas que, desafortunadamente, impiden la fácil penetración de los servicios hasta el nivel del ciudadano común.

Todo ello se erige en un obstáculo para el funcionamiento de la infraestructura de firma digital, pues dificulta grandemente el acceso al goce de las presunciones que se otorgan a la firma digital. A la fecha, cuatro entidades han obtenido la licencia para actuar como entes certificadores: AFIP, ANSES, ONTI, y ENCODA SA, esta última es la única de carácter privado.

La Cámara Nacional de Apelaciones en lo Comercial tiene dicho que la falta de firma digital remueve el valor probatorio de un correo electrónico ${ }^{22}$, estableciendo una regla aún más estricta a la mandada por la ley, por vía jurisprudencial, obviando la posibilidad de probar la veracidad del documento por otros medios. Sin embargo este precedente se enfrenta a otros que le otorgan validez a los documentos electrónicos aún a falta de firma digital, siempre y cuando existan medios coadyuvantes. Ello demuestra un estado de

\footnotetext{
${ }^{22}$ Henry Hirschen y Cía. S.A. c. Easy Argentina S.R.L. (Cámara Nacional de Apelaciones en lo Comercial Sala D. 16 de febrero de 2007).
} 


\section{LA EFICACIA DEL CORREO ELECTRÓNICO COMO MEDIO DE CONFIRMACIÓN EN EL PROCESO CIVIL Y COMERCIAL}

evolución veloz en los estrados tribunalicios, todo esto se verá en más detalle en el apartado correspondiente.

La cuestión de la firma digital, la criptografía en general, y su recepción en el ordenamiento jurídico argentino puede ser analizado con muchísima más profundidad, y tiene elementos y sutilezas que exceden este trabajo, hasta aquí se ha intentado dar una somera referencia de su funcionamiento elemental y de sus características más sobresaliente para entender la forma en que su aplicación puede influir en el valor probatorio de los correos electrónicos como documentos digitales.

\section{La Prueba en materia informática}

Hasta aquí se han analizados los requisitos y elementos de los documentos electrónicos en sí mismos, con algunas referencias cómo esos aspectos relativas a la modalidad en que estos aspectos gravitan en la faz procesal probatoria.

Con esos conceptos ya vistos, se puede ahora ingresar en el análisis más pormenorizado de esa etapa del proceso, viendo ahora con mayor claridad los detalles y particularidades que los especiales caracteres del objeto de estudio incorporan.

\section{Prueba de los actos jurídicos}

Si bien los requisitos de forma de los actos jurídicos en general no presentan obstáculos insalvables, para la validez de los realizados por medios electrónicos, la prueba de aquellos puede presentarse con mayor complejidad.

Para comenzar por el principio, se verá antes que nada, la prueba en si misma, con consideraciones conceptuales que luego redundaran en mayor claridad para definir el valor probatorio de lo que se estudia.

Probar algo es demostrar la veracidad de un hecho, más precisamente "es la demostración, por alguno de los medios que la ley establece [...], de la verdad de un hecho del cual depende la existencia de un derecho" ${ }^{23}$. Como corolario se puede afirmar que de la prueba de un acto jurídico no depende su existencia. Así, un acto jurídico puede gozar de plena validez según los requisitos de forma que para él se exigen, pero posiblemente no existan aún los medios para probarlo.

\footnotetext{
${ }^{23}$ Altmark D. R. \& Molina Quiroga E. Op. Cit. pág. 525
} 


\section{LA EFICACIA DEL CORREO ELECTRÓNICO COMO MEDIO DE CONFIRMACIÓN EN EL PROCESO CIVIL Y COMERCIAL}

Sin embargo, el término "prueba" no es univocó, puede hablarse de prueba en términos de estricta incontestabilidad o, en un sentido más subjetivo, de convicción o acreditación. También puede referirse a la prueba como medio o como resultado.

Más aún, puede hablarse de una prueba científica, que otorga una veracidad irremediable a las proposiciones que demuestra, $y$, en contraposición, no puede predicarse la indubitabilidad de ciertas pruebas judiciales como la testimonial.

Para enfocar la cuestión lo más posible, valgan algunas precisiones: Según Rodriguez Saiach, probar, en términos jurídicos, es acreditar legalmente la existencia y condiciones de un hecho, en el marco de un proceso judicial. Además, esa prueba debe referirse a hechos esgrimidos por las partes, controvertidos, y conducentes a la resolución del litigio ${ }^{24}$.

Es decir que la prueba ofrecida debe referirse a hechos que una de las partes alegue y que a su vez estén contradichos por hechos afirmados por la contraparte. Asimismo, estos deben ser hechos relevantes para elucidar las pretensiones de ellas, pues no cualquier hecho es de importancia para la fijación de los derechos de las partes.

Para despejar algunas imprecisiones conceptuales, se seguirá a Alvarado Velloso en este aspecto, prefiriendo "el uso del vocablo confirmación (significa reafirmar una probabilidad): en rigor, una afirmación negada se confirma con diversos medios que pueden generar convicción (no certeza o crédito) a un juzgador en tanto que no la generan en otro" 25 . En este sentido, cuando se utilice el término prueba se estará haciendo referencia a esta concepción limitada del vocablo.

Tradicionalmente se acepta que el rol del juzgador en el proceso es fijar los hechos y aplicar la norma correspondiente a la pretensión deducida. Sin embargo, al enfrentarse esta concepción con la posibilidad de que los hechos, aceptados como tales en el proceso, no coincidan con los cumplidos en la realidad de la vida social, se suscita una fuerte crítica, que en su momento dio lugar al surgimiento del sistema inquisitivo.

Ello fue la causa de que la doctrina elaborara la distinción entre verdad formal y la verdad real. La primera siendo la descripción de los hechos realizada por el juez en la sentencia,

\footnotetext{
${ }^{24}$ Rodriguez Saiach, V. M. (2014). Prueba y Carga de la Prueba en Materia Informática. Buenos Aires: Gowa. Pág. 25

${ }^{25}$ Alvarado Velloso, A., \& Gonzalez Castro, M. A. Op. Cit. Pág. 534
} 


\section{LA EFICACIA DEL CORREO ELECTRÓNICO COMO MEDIO DE CONFIRMACIÓN EN EL PROCESO CIVIL Y COMERCIAL}

propia del sistema dispositivo. La segunda, la plena coincidencia entre lo sentenciado y lo acaecido en la realidad objetiva, propia del sistema inquisitivo.

Esta distinción plantea roles radicalmente distintos para el juzgador. En el supuesto de la verdad formal, aquel otorga certeza de las relaciones jurídicas a partir de las posiciones de las partes, aceptando lo que ellas afirman, lo que permite apaciguarlas y restaurar así la paz social. En el otro supuesto, el juez actúa como un investigador que intenta procurar la verdad, para lograr alcanzar la Justicia, conforme lo que él entiende que es ese valor.

Este problema se potencia al entender que se trata de un enfrentamiento entre dos posturas filosóficas radicalmente distintas, por un lado se tiene una visión del mundo en el que existe, sin lugar a dudas, una única y absoluta verdad, que puede ser accedida por medio de los sentidos y demostrada por las huellas que los hechos dejan en el mundo. Por el otro, se plantea un relativismo que propone que cada individuo posee sólo un corte de la realidad, sesgado por sus percepciones y, por lo tanto, no puede afirmarse una Verdad absoluta-

Este es un debate nunca completamente acabado, y posiblemente esto sea la causa de que no existan en la realidad normativa sistemas puramente dispositivos o inquisitivos.

Sin embargo, más allá de los devaneos iusfilosóficos posibles, el juzgador, ante el enfrentamiento de afirmaciones fácticas de las partes, ha de de llegar a una conclusión, una sentencia que cree una norma individualizada que rija en el futuro a las partes en litigio, y para poder hacerlo debe realizar una tarea de análisis histórico de los hechos.

De ello se desprende la extrema importancia de que la ley regule con todo detalle las cuestiones de: qué puede ser confirmado, de dónde se extraerá la confirmación, qué debe ser confirmado, quién debe confirmar, cómo ha de confirmarse, y cuándo y dónde ha de hacerse la confirmación.

\section{El objeto de la prueba}

Para responder a la cuestión de qué puede confirmarse hay que recordar lo que se dijo respecto de la afirmación que se realiza al momento del planteo de la demanda, esa afirmación se refiere a hechos materiales acaecidos, por lo tanto, hechos formales tales como la existencia y vigencia de la ley no son susceptibles de ser probados.

"de este modo, constituyen verdaderos hechos a los fines

confirmatorios todas las expresiones de la ley en sentido material no 


\section{LA EFICACIA DEL CORREO ELECTRÓNICO COMO MEDIO DE CONFIRMACIÓN EN EL PROCESO CIVIL Y COMERCIAL}

formal: las resoluciones generales no publicadas en el Boletín Oficial respectivo, las ordenanzas municipales, los convenios colectivos de trabajo, los usos y la costumbre, etc. $Y$, por supuesto, la ley extranjera en cualquiera de sus formas ${ }^{, 26}$

En el caso de los correos electrónicos, estos pueden indicar los hechos a probar, o ser en sí mismos los hechos que se han de probar, según sea el caso la gravitación que tendrán como elemento de convicción podrá variar.

Ahora bien, no todo lo que puede ser confirmado debe serlo, para ello, se debe analizar la cuestión del tema de la confirmación.

\section{El tema de confirmación o prueba}

La etapa confirmatoria en el proceso sigue a la etapa de la negación o contestación de la afirmación o demanda. En aquel momento es que se define el ámbito de contradicción de los hechos que indicará qué es aquello que debe ser confirmado, el tema sobre el cuál versará la prueba pertinente.

Si no existe una negación de los hechos afirmados, el proceso deviene en los que se llama "de puro derecho" pues no se requiere en el mismo la presentación de medios probatorios para confirmar la versión de ninguna de las partes.

A esa situación de falta de controversia se equiparan otras situaciones como lo son la falta de negación específica o admisión tácita de los hechos. Por cierto, lógicamente quedan equiparados a los de esta especie los hechos admitidos y los hechos presumidos por la ley. Por otro lado, si hubo negación de los hechos, de todos los hechos que pueden ser probados, sólo deben serlo aquellos que están controvertidos, es decir aquellos que son afirmados por una de las partes y negados por la otra.

Además, existe el supuesto en que los hechos deben ser confirmados aún cuando no hayan sido controvertidos. Estos supuestos son cuando esté comprometido el orden público y cuando haya respuesta en expectativa de los defensores de ausentes. En ambos casos la confirmación debe darse como si los hechos estuviesen controvertidos.

${ }^{26}$ Ídem. Pág 542 


\section{LA EFICACIA DEL CORREO ELECTRÓNICO COMO MEDIO DE CONFIRMACIÓN EN EL PROCESO CIVIL Y COMERCIAL}

Hay otros hechos que, aún siendo negados y controvertidos, no deben ser confirmados, se trata de los hechos evidentes, los normales, los presumidos por ley, y los negativos.

Los hechos evidentes son aquellos conocidos por todos los integrantes de una sociedad dada y que no admiten controversia razonable, tal como la disminución de la visibilidad durante la noche.

Los normales son aquellos que se dan habitualmente y son aceptados por la mayor parte de la sociedad, se refieren a la conducta normal del grupo social.

Resulta evidente que cualquier persona, cuando observa que algo se produce, en la totalidad o en la gran mayoría de los casos, de la misma forma, generalizará ese supuesto a todo otro similar, entendiendo que es muy probable que ocurra en el caso particular lo que ocurre en la generalidad de los casos.

Los hechos notorios son aquellos que el juzgador puede conocer por si mismo independientemente de las afirmaciones de las partes, este concepto es grandemente discutido pues entorpece los principios del sistema dispositivo.

Los presumidos por la ley son los que la ley acepta como verdaderos, admitiendo prueba en contrario (iuris tantum) o no (iure et de iure).

Por último, los hechos negativos son aquellos que importan la afirmación de la ausencia de una calidad o cualidad, o de una omisión. Estos no pueden ser demostrados directamente, y sólo admiten demostración lógica indirecta, por lo que no se exige que estos hechos sean probados, aunque nada impide que se ofrezcan medios probatorios indirectos para sustentar, cuanto menos indiciariamente, la afirmación negativa.

Los e-mail pueden ser utilizados para demostrar cualquiera de aquellos hechos. Incluso pueden poseer características de aquellos, como los correos electrónicos que posean firma digital tendrán la presunción de haber sido emitidos por el dueño del certificado digital usado.

\section{La fuente de la confirmación}

Es importante distinguir dos conceptos que usualmente se confunden cuando se trata el tema de la fuente de la prueba o confirmación, estos son la fuente propiamente dicha y el medio de confirmación. 


\section{LA EFICACIA DEL CORREO ELECTRÓNICO COMO MEDIO DE CONFIRMACIÓN EN EL PROCESO CIVIL Y COMERCIAL}

Fuente es el objeto o persona que provee la información sobre el tema a confirmar, medio es el modo en que esa información es acercada al juzgador. Por ejemplo, un testigo, la persona que declara, es la fuente de confirmación, su declaración, es el medio por el que esa información es conocida por el juez.

Habiendo hecho esa distinción, se pueden mencionar algunas fuentes de confirmación comunes a los procesos judiciales, tales como las personas que conozcan y puedan declarar acerca de los hechos controvertidos en juicio, las mismas partes del proceso. En estos casos los medios serán los testimonios, las confesiones, o los peritajes. Las personas jurídicas, a través de la expedición de informes o exposición de sus libros también pueden ser fuente de confirmación.

Los documentos, como ya se ha desarrollado anteriormente, son fuentes de información cuyo medio de producción es la documental o informativa.

En este sentido los correos electrónicos no poseen mayores particularidades, aunque variaran respecto de algunos medios de confirmación conexos, tales como el peritaje caligráfico en un documento tradicional no se aplicaría a un documento electrónico.

Otras fuentes de confirmación pueden ser los lugares, cosas o personas que pueden ser percibidos directamente por el juzgador a través de sus sentidos, el medio será el reconocimiento que el juzgador pueda hacer de tales personas, cosas o lugares por vía de la inspección ocular.

\section{La incumbencia de la confirmación}

La cuestión de quién debe probar qué hechos en un proceso no es para nada pacífica en la doctrina y la jurisprudencia. Este asunto se remonta a la necesidad de establecer reglas claras para el juzgador de cómo debe actuar ante la falta de confirmación suficiente de los hechos del pleito.

Otrora, el sistema era establecido subjetivamente por el pretor, quien imponía las cargas probatorias según quien considerara se encontraba en mejor situación para proveer la prueba. Sin embargo, este sistema adolecía de recaer exclusivamente en la percepción del pretor, lo que abría la puerta a innumerables injusticias.

Es por aquellos inconvenientes que esa práctica fue abandonada, estableciéndose la regla de que quien afirmaba el hecho litigioso debía confirmarlo. Esa regla se ha plasmado en la 


\section{LA EFICACIA DEL CORREO ELECTRÓNICO COMO MEDIO DE CONFIRMACIÓN EN EL PROCESO CIVIL Y COMERCIAL}

legislación moderna imponiendo "la carga a cada una de las partes respecto de los presupuestos de hecho de la norma jurídica que le es favorable"27.

De este modo, quien afirma un hecho constitutivo, extintivo, invalidativo o convalidativo, o impeditivo deberá probarlo, no importando que sea el actor o demandado, pues cualquier a de las partes debe demostrar el hecho por el cual la norma le favorece.

Para mayor claridad, se entiende por hecho constitutivo aquel que hace emerger el derecho que se pretende; hecho extintivo es el que libera de responsabilidad pues el derecho, que surgió de aquel constitutivo, ha perecido por este.

Por otra parte, hecho invalidativo es el que remueve validez al hecho extintivo, y hecho convalidativo es el que le devolverá la validez. Como se puede observar estas categorías son coincidentes con la cadena de pretensiones y excepciones que se pueden esgrimir en un determinado proceso, pendiendo el resultado final del litigio de la fuerza con que cada parte logre dar a los eslabones que le favorecen. Por ejemplo, si el actor que pretende un pago, lograr demostrar que la entrega de dinero que hizo el demandado no fue válida (hecho invalidativo) ganará su pretensión; pero si no lo hace y el hecho extintivo (pago) fue confirmado, pues el demandado saldrá victorioso.

Por último cabe aclarar que hecho impeditivo se refiere a la ausencia de requisitos esenciales de los hechos constitutivos, son aquellos que no atacan a un momento de la cadena lógica de actos jurídicos, sino a la relación jurídica en si misma desde su origen (capacidad de las personas, discernimiento, etc.). También se refiere a los hechos que quitan eficacia al proceso para resolver el conflicto, es decir las excepciones procesales.

\section{Los medios de confirmación}

Siguiendo a Alvarado Velloso, se expondrán no tanto los medios tradicionalmente reconocidos de prueba (documental, confesional, peritaje, etc.) sino que se optará por un método más sistematizado, que plantea cuatro medios de confirmación según el grado de eficacia confirmatoria que ofrecen, "se denominan:

- De comprobación (producen certeza)

- De acreditación (producen verosimilitud)

- De mostración (producen percepción)

${ }^{27}$ Ídem. Pág. 250 


\section{LA EFICACIA DEL CORREO ELECTRÓNICO COMO MEDIO DE CONFIRMACIÓN EN EL PROCESO CIVIL Y COMERCIAL}

\section{- De convicción (producen probabilidad)"28}

Los medios de comprobación son aquellos que logran dar certeza científica de los hechos que demuestran, son hechos de los cuales, por el estado de la ciencia respectiva, puede predicarse una verdad objetiva absoluta en todo tiempo y lugar, tras haberse realizado los procedimientos experimentales necesarios para arribar a ella.

Es por ello que este medio se obtiene tras la realización de un trabajo científico y técnico, sobre un hecho litigioso que puede ser comprobado por estos medios científicos.

Dada sus características estos medios de prueba suelen ser sumamente restringidos, aunque son los más deseables durante un proceso, pues al juez no le es dado apartarse de lo que estos medios predican, y producen prueba propiamente dicha.

La acreditación es un medio confirmatorio que plasma en el presente un hecho o relación jurídica para su futura demostración, es dejar constancia de lo que ha sucedido. Su valor probatorio suele surgir de la creencia de legitimidad que le otorgan las leyes a las constancias producidas observando las formalidades exigidas.

Usualmente los medios de acreditación son los documentos, sin embargo, hoy existen innumerables medios de constatación que no son estrictamente documentos, tales como los instrumentos o registros Anteriormente se han desarrollado estos conceptos, por lo que se remite a aquel apartado por razones de brevedad.

La mostración es el medio por el cual el juez accede directamente a los hechos a confirmar, suele ser llamado prueba directa. Se trata esencialmente de poner a la vista cosas, lugares, o personas para que el juzgador los perciba por sus propios sentidos.

Es un medio que plantea cuestionamientos sobre la objetividad del juzgador, pues él mismo se erige como sujeto de la confirmación, ello trae problemas por partida doble. Por un lado está la cuestión de que el juzgador puede percibir las cosas de modo diferente a lo que las partes quieren mostrarle. Y por otro, la cuestión de que el juez puede fijar los hechos en su fuero interno sin la menor posibilidad de control por parte de los interesados.

Finalmente, la convicción, que es la "seguridad de algo que parece lógico racionalmente [...] Es el fenómeno interno que se produce en la mente del juzgador que posibilita la 


\section{LA EFICACIA DEL CORREO ELECTRÓNICO COMO MEDIO DE CONFIRMACIÓN EN EL PROCESO CIVIL Y COMERCIAL}

inclinación de su ánimo hacia la aceptación como probable de una afirmación"29. Se puede observar claramente que es un medio confirmatorio netamente subjetivo, por lo que idealmente sólo debe ser utilizado cuando no existan otros medios confirmatorios más certeros.

Los medios serán aquellos que el juez pueda percibir por sus sentidos o inferir por su razonamiento: declaraciones, confesiones, documentos simples comprobados por testigos, o indicios.

\section{Los documentos como medios de confirmación}

Se ha visto la cuestión de la confirmación en rasgos generales, a continuación se verá en particular cómo se manifiesta el asunto de la confirmación respecto de los documentos.

Vale hacer una aclaración previa, las normas que rigen lo relativo al valor confirmatorio de los documentos se encuentran dispersas por todo el ordenamiento jurídico nacional, estando numerosas de esas normas contenidas en los códigos de fondo en lugar de los códigos de procedimiento.

Se analizarán los requisitos de existencia, validez y eficacia probatoria de los documentos en general, aplicándolos luego, en particular a los correos electrónicos.

\section{Requisitos de existencia}

Los requisitos de existencia de los documentos son:

- Que se hayan realizado por un acto humano

- Que tengan significación propia y entidad confirmatoria

Obsérvese que la firma no deviene en un requisito de existencia, pues al tratarse la cuestión de documentos en sentido amplio, es evidente que no todos ellos requerirán de firma, tales como un monumento (un mojón por ejemplo), por lo que su existencia no es contingente en la presencia de una firma.

Además, el problema de la firma se circunscribe a los documentos privados, téngase presente que un billete de papel moneda no posee firma original. Al respecto se mencionó que la exigencia de la firma para la existencia de algunos documentos privados complejiza en gran modo las relaciones actuales, tales como los contratos que se realizan por medios informáticos, como ya se ha visto.

${ }^{29}$ Ídem. Pág. 565 


\section{LA EFICACIA DEL CORREO ELECTRÓNICO COMO MEDIO DE CONFIRMACIÓN EN EL PROCESO CIVIL Y COMERCIAL}

Sin embargo, vale aclarar que cuando se habla de un documento escrito, que requiere para su existencia de la presencia de firma, pues en ese caso esta será un requisito de existencia. En estos casos, serán válidas las consideraciones hechas al respecto de la equiparación de la firma ológrafa a las firmas digital y electrónica (con sus respectivas diferencias).

Requisitos de validez

Son necesarios para la validez de los documentos:

- Que se haya elaborado voluntariamente

- Que posea las formalidades legales, y se acerque al proceso legítimamente, cumpliendo las formalidades de modo, tiempo y lugar exigidos por la norma

- Presentación de los documentos por la parte

Los documentos pueden ser presentados en cualquier estado del pleito, "pero si lo fuesen luego de haber llamado los autos no serán admitidos, salvo que sean de fecha posterior o que llevando fecha anterior se exprese bajo juramento o, en su caso, afirmación de no haberlos conocido o podido obtener oportunamente." (art. 241inc. 1 CPCC).

En segunda instancia en los mismos términos, hasta el llamamiento de autos.

- Exhibición de documentos por la contraparte o terceros

La contraparte tiene la carga de exhibir los documentos relativos a la cuestión litigiosa que estén en su poder o, caso contrario, de identificar el lugar donde se hallan. "la negativa de las partes o el incumplimiento de la obligación de exhibirlos dentro del plazo que se le fije constituirá presunción en su contra, si de otros elementos de juicio resulte verosímil su existencia y contenido" (art. 253 CPCC).

- Reconocimiento y desconocimiento de firma

"Para la eficacia de los documentos privados, se requiere que sean reconocidos por la persona contra quien se presenten o que el tribunal los declare tales." (art. 248 CPCC)

El desconocimiento de la firma de un documento privado da lugar al diligenciamiento de la pericial caligráfica implícita en todo ofrecimiento de prueba documental (art. 242 CPCC). 


\section{LA EFICACIA DEL CORREO ELECTRÓNICO COMO MEDIO DE CONFIRMACIÓN EN EL PROCESO CIVIL Y COMERCIAL}

Si bien el código prevé el ofrecimiento tácito de la pericial caligráfica para los documentos en soporte papel, no queda claro si esa misma norma puede entenderse extensiva para incluir un peritaje técnico en el caso de los documentos electrónicos, por lo que sería aconsejable siempre ofrecerlo expresamente al momento de presentar uno de ellos como medio de confirmación en juicio.

Los requisitos de eficacia del documento

Son requisitos para la eficacia de los documentos:

- Que su contenido sea convincente.

- Que no haya otro medio confirmatorio válido en su contra.

- Que llegue al proceso sin violar el deber de secreto que la ley le imponga a su emisor o tenedor.

- Que este completo, sin alteraciones, mutilaciones, tachaduras o enmiendas sin salvar adecuadamente por el emisor o con la misma máquina con la cual se emitió.

- En su caso, que se haya hecho el registro que exija la ley.

- Si fue emitido en el extranjero, que posea todos los requisitos exigidos para su elaboración y autenticidad: “Los documentos públicos otorgados en el extranjero, hechos con arreglo a las leyes del país respectivo, autenticados y legalizados en debida forma, producirán la misma prueba que los otorgados en la República, si su objeto fuere lícito y permitido por las leyes argentinas" (art. 245 CPCC).

\section{La jurisprudencia en torno a los correos electrónicos}

Antes de adentrarse de lleno en la lectura de los casos particulares que se presentan, es necesario recordar el criterio que manda a los jueces la forma de valoración de la prueba que se trae ante él.

Ese criterio es el de la sana crítica racional, y vale revisar su conceptualización para luego poder hacer un análisis más atento de las conclusiones a las que llegaron los tribunales en los casos jurisprudenciales mostrados.

La sana crítica racional

El sistema que rige al juzgador para la valoración de la prueba al momento de dictar sentencia es el sistema de convicción y fundamentación según la sana crítica racional. 


\section{LA EFICACIA DEL CORREO ELECTRÓNICO COMO MEDIO DE CONFIRMACIÓN EN EL PROCESO CIVIL Y COMERCIAL}

Este sistema se opone a otros en los que la prueba se encuentra tasada o preordenada por la ley, y de los sistemas en que nada tiene que explicar el juez sobre cómo arriba a la convicción que funda su sentencia.

En una suerte de posición a medio camino entre un sistema puramente aritmético y uno netamente subjetivo, el juez debe explicar con la mayor prolijidad posible, por mandato de la ley, las razones por las que llega a su conclusión. Ello para lograr que quien pierda en definitiva el pleito quede persuadido de la justicia de lo resuelto.

Una importante doctrina sostiene que la sana crítica exige que el juzgador piense y describa su razonamiento de modo tal que permita al perdedor comprender las razones objetivas y subjetivas que influyeron en su ánimo al tomar la decisión que le es adversa y, además, posibilitar al superior igual conocimiento para que pueda saber lo mismo y, eventualmente, atender a los agravios del impugnante. De ello se sigue que la valoración conforme a la sana crítica racional al día de hoy no es una técnica exclusiva sino que es la resultante de una combinación que reúne desde el valor anticipado de los medios de confirmación a la libre convicción en las declaraciones, para llegar a la ponderación final de todos los medios de eficiencia regularmente llevados al proceso.

\section{Reconocimiento de los correos electrónicos}

Al respecto del reconocimiento de los correos electrónicos que son presentados como prueba en un proceso judicial, la Cámara Nacional de Apelaciones en lo Comercial, por el voto del Dr. Ojea Quintana, afirmó en Ketra SRL contra Omda SA que

"la testigo declaró y le fue requerido expresamente que se expidiese respecto de la autenticidad de los mails y admitió que había sido ella quien los remitió. Sobre tales bases, cuadra tener por auténticos los correos en cuestión. Obsérvese que, frente al reconocimiento de los correos, pretender cargar consecuencias negativas a la defendida por la supuesta omisión de efectuar sobre ellos una pericial de informática, importaría, por vía elíptica, hacerla cargar con la prueba de un hecho negativo: la no alteración de los mails. Tanto más ello es así, si se considera que, acecido lo regular (reconocimiento de los mails por la 


\section{LA EFICACIA DEL CORREO ELECTRÓNICO COMO MEDIO DE CONFIRMACIÓN EN EL PROCESO CIVIL Y COMERCIAL}

testigo que los envió), no cabe presumir sin prueba la ocurrencia de lo inusual (la alteración del contenido de los correos)" 30

El texto citado demuestra cómo, en el marco de un proceso, los correos electrónicos pueden funcionar como prueba de lo alegado por las partes, aunque también demuestran la necesidad de reconocimiento de los mismos. Sin embargo, ello no es extraño a otras clases de documentos privados que carezcan de la fe pública que pueden disfrutar algunos instrumentos.

En el mismo fallo, el Dr. Barreiro, también se explaya en las razones que dan validez al correo electrónico como prueba en el proceso:

\section{“[...]1) el desconocimiento efectuado por la actora del contenido} de los mails luce sumamente endeble; 2) iguales grietas presenta el testimonio rendido por la empleada de la actora que habría sido la autora de esos correos electrónicos; 3)tales mails, de todos modos, constituyen un principio de prueba por escrito que debe ponderarse en concordancia con el plexo probatorio obrante en la causa,31

Nótese como en su razonamiento, el Dr. Barreiro, introduce un elemento de suma importancia al momento de valorar el e-mail como prueba, pues al indicar las grietas en el desconocimiento por parte de la actora del contenido de los correos, exige que aquel sea consistente y suficiente para enervar la fuerza probatoria del documento, que por leve que pudiera ser merece más que una simple negación para ser desplazado. Así se plasman dos extremos del valor probatorio de los correos electrónicos, por un lado su reconocimiento los fortalece en su fuerza probatoria, y por el otro su mero desconocimiento no basta para removérsela por completo.

Importancia de los correos electrónicos en diversos procesos

El uso de los correos electrónicos ha servido en numerosos casos como medio para probar hechos que cimentaron las pretensiones de las partes. A continuación se hará una transcripción de algunos casos en los que se pone de manifiesto la utilidad de esta herramienta probatoria

\footnotetext{
${ }^{30}$ Ketra SRL c/ Omda SA s/ Ordinario (Cámara Nacional de Apelaciones en lo Comercial - Sala F 13 de 09 de 2012)

31 Ídem.
} 


\section{LA EFICACIA DEL CORREO ELECTRÓNICO COMO MEDIO DE CONFIRMACIÓN EN EL PROCESO CIVIL Y COMERCIAL}

Divorcio, e-mail como prueba de injurias

Tiene dicho la Cámara Nacional de Apelaciones, Sala G:

"Más allá de la posibilidad cierta de alteración de los correos electrónicos y del eventual acceso de la esposa a la casilla de su consorte, si los e-mails dan cuenta de un vínculo afectivo del demandado con otra mujer pero por su contenido no alcanzan para tener por configurada la causal de adulterio, sino que demuestran la existencia de relaciones incompatibles con la exclusividad del matrimonio, corresponde incluirlas en el inc. 4 del art. 202 del Código Civil",32

Véase como incluso el acceso de la esposa a los correos no es suficiente para borrar el valor probatorio de los mails presentados como prueba.

Injurias por la profusión de correos

"Las llamadas y mensajes de texto habidos entre uno de los cónyuges y un tercer configuran indicios graves, precisos y concordantes respecto de una relación extramatrimonial cuando - aún no habiendo sido probado su contenido-son tan numerosas y frecuentes que denotan una necesidad de comunicación entre ambos por no ser habituales entre personas que no están vinculadas por un lazo afectivo [...] ahora bien, sin perjuicio de la forma de obtención de la comunicación a través de internet, corresponde descartar los e-mails obtenidos como prueba, si de la pericia surge que pueden haber sido modificados antes de su impresión. Es que, no basta solamente el reconocimiento de la dirección de correo electrónico por parte de un testigo para acreditar que esa fue la correspondencia habida entre las partes ${ }^{33}$

En este caso se muestran dos cuestiones interesantes, por un lado la posibilidad de que los correos electrónicos, en sí mismos, como prueba de la existencia de una abundante comunicación entre dos personas, pueden fundar la plataforma fáctica de un proceso. Lo

\footnotetext{
${ }^{32}$ M., M.L. c/ L., J.H. s/ Divorcio, G588911 (Cámara Nacional de Apelaciones en lo Civil - Sala G 12 de 04 de 2012)

${ }^{33}$ B., T.E. c/ Q., C.N. s/ Divorcio, J072102 (Cámara Nacional de Apelaciones en lo Civil - Sala J 06 de 10 de 2011).
} 


\section{LA EFICACIA DEL CORREO ELECTRÓNICO COMO MEDIO DE CONFIRMACIÓN EN EL PROCESO CIVIL Y COMERCIAL}

que remite a lo ya expresado sobre la multiplicidad de niveles de información que proveen estos medios de comunicación, y como estos por sí pueden erigirse como hechos jurídicamente relevantes, trascendiendo la información contenida en ellos.

Otro punto a tener en cuenta es un límite a la fuerza probatoria que poseen, en especial cuando otro medio de prueba, de tipo científico como lo es un peritaje, se encuentra en conflicto con los mismos. Ello es demostrativo de que no son por sí mismos medios de confirmación que provean de absoluta certeza.

El e-mail como causal de despido

En un caso en el que un empleado de un banco reenvió, usando una cuenta institucional, un correo alertando de un posible corralito financiero, y por el cual se lo despidió, la Cámara Nacional del Trabajo Sala II dijo: "aún cuando en el recurso se le impute al accionante una parte de la autoría del contenido del mail [...] lo cierto es que ello no constituye más que una inferencia o apreciación de parte sin respaldo probatorio alguno dado que la accionada omite toda referencia a los elementos de juicio obrantes en autos en sustento de su subjetivo punto de vista, que permitan corroborar su tesis.

Pero, más allá de esta cuestión vinculada con la autoría intelectual de la falsa información difundida, lo cierto es que la difusión, por parte del actor y a través del mail institucional, del correo que alertaba a los destinatarios sobre la inminente confiscación del dinero depositado en los bancos cuyas consecuencias resultarían más gravosas aún que el denominado "Corralito Financiero" del año 2001, importó una clara violación a los deberes de fidelidad y reserva.

En efecto, no puedo soslayar que al tratarse de un empleado del banco, con categoría de "Jefe" y una antigüedad de 15 años, el envío de un correo electrónico del tenor transcripto emitido desde la casilla institucional del banco y en el cual, el actor, no desmentía la falsa información ni atribuía la autoría a un tercero al tiempo que instaba veladamente al retiro de los fondos depositados en los bancos ("gracias a estos avisos algunos pudieron zafar del primer corralito”) configuró, a mi juicio, una grave injuria a los intereses del empleador que legitimó la medida dispuesta por el principal. "34

\footnotetext{
${ }^{34}$ M., M.G. c/ HSBC Bank Argentina S.A. s/ despido, 25.206/2008 (Cámara Nacional del Trabajo - Sala II 26 de 11 de 2010).
} 


\section{LA EFICACIA DEL CORREO ELECTRÓNICO COMO MEDIO DE CONFIRMACIÓN EN EL PROCESO CIVIL Y COMERCIAL}

Nuevamente se puede apreciar como el correo electrónico, en este caso independientemente de la autoría del mismo por parte del remitente, es fundamento suficiente para justificar la pretensión de una de las partes. Cabe aclarar que en este caso el empleado despedido reconoció haber enviado los correos que sirvieron de prueba al banco.

\section{Identificación del remitente}

Como se ha mencionado cuando se habló de firma digital, la cuestión de la identificación del remitente de los correos es de esencial importancia para la utilización de estos documentos como medios de confirmación. En tal sentido, en Mullins contra Stratford, la Cámara Nacional del Trabajo Sala VIII expresó que "la copia de los mails acompañados por la quejosa no son hábiles para arribar a una razonable conclusión sobre los hechos expuestos. Si bien los informes de los hoteles confirman que aquellos fueron enviados por la empresa S.B.S., ellos no son eficaces para identificar la persona que los remitió, máxime cuando la dirección de la casilla estaba bajo el nombre "Parque Chacabuco". Si bien en el contenido de los mails figura al final del texto el nombre "Maureen", apodo de la actora, el mismo no se asimila a la firma digital, por lo que no tiene más valor que el de un indicio ",35.

Aquí se muestra prístina la necesidad de avanzar en la implementación de la infraestructura de firma digital, para poder contar con un medio legalmente idóneo para demostrar la identidad de los remitentes de los documentos electrónicos.

\section{Corroboración de los correos por testigos}

En un caso de recisión unilateral de contrato, en donde se discutía el suficiente aviso sobre la voluntad de rescindir el contrato, la Cámara Nacional en lo Comercial Sala E dijo que "el intercambio de e-mails denota un punto de inflexión en la relación de las partes originado por desacuerdos relacionados con la inspección ocular de los rodados a asegurar, lo cual motivó en el actor su deseo de cambiar de asesor, así como también cierto descontento con la calidad del servicio recibido. La prueba testimonial corroboraría esta situación. ”36.

\footnotetext{
${ }^{35}$ Mullins, María E. c/ Stratford Book Services S.A. s/ Despido, 18885/2004 (Cámara Nacional del Trabajo Sala VIII 31 de 10 de 2005)

${ }^{36}$ Arrieta, Eduardo R. c/ Allianz Argentina Cía de Seguros Generales S.A. s/ ordinario (Cámara Nacional de Apelaciones en lo Comercial - Sala E 26 de 11 de 2010)
} 


\section{LA EFICACIA DEL CORREO ELECTRÓNICO COMO MEDIO DE CONFIRMACIÓN EN EL PROCESO CIVIL Y COMERCIAL}

Se percibe claramente una línea jurisprudencial general, en la que la fuerza confirmatoria de los correos electrónicos se ve potenciada cuando se manifiesta concordante con otros medios de prueba de igual, o incluso menor, poder probatorio.

\section{Los correos electrónicos no sirven como recibo}

La misma Cámara, en su Sala A, dijo al respecto de los e-mail cuando se los presentó como recibos de pago: "No puede admitirse que ciertos mails, tal como se pretende en el caso, demuestren el supuesto pago parcial de cierta obligación cambiaría, habida cuenta que el medio requerido para ello lo constituye el recibo extendido por el acreedor que aluda, en forma clara y precisa, a la obligación que se ejecuta, es decir, consignando la deuda saldada. Ergo, resulta impropia la prueba aportada por el excepcionante para fundamentar su defensa, en tanto los aludidos mensajes no conforman un documento apto para acreditar pagos imputables a la deuda que se ejecuta, en los términos exigido, en un proceso de naturaleza ejecutiva por la legislación adjetiva",37.

En nada puede cuestionarse lo dicho por la Cámara, en tanto lo mismo habría sido apropiado para cualquier otro documento que no revistiera de las formalidades requeridas para el acto que pretende contener. Nótese que la Cámara nada dice respecto de la posibilidad de que el e-mail posea esas cualidades en términos generales, sino que sólo en este caso en particular no las revestía, y tratándose de un juicio ejecutivo, las formalidades reinan.

\section{Las palabras de los tribunales}

Como se ha visto por este paseo por diversos casos jurisprudenciales, el criterio generalizado es el de la validez, prima facie, de los correos electrónicos como medios de confirmación.

No obstante aquello, queda en evidencia que estos no se erigen en medios de confirmación científicos de la información que contienen, sino que tienen el poder de convicción de cualquier documento privado, por lo que, si bien pueden ofrecer un valor probatorio por sí mismos, se potencian al encontrarse sostenidos por otros medios que fortalezcan el plexo confirmatorio del expediente.

\footnotetext{
${ }^{37}$ Silva Calabretta, Luis Ernesto c/ Musmanno, Claudio Darío s/ ejecutivo (Cámara Nacional de Apelaciones en lo Comercial - Sala A 04 de 04 de 2013)
}

\begin{tabular}{llll}
\hline \hline ANUARIO DE DERECHO CIVIL & TOMO XIII & 2019 & Página 46
\end{tabular}




\section{LA EFICACIA DEL CORREO ELECTRÓNICO COMO MEDIO DE CONFIRMACIÓN EN EL PROCESO CIVIL Y COMERCIAL}

Por ello se puede decir que, al menos jurisprudencialmente, los correos electrónicos no poseen una capacidad probatoria absoluta, pero ello no significa que no posean capacidad confirmatoria, sino que será relativa y que podrá ser conmovida ya sea por otros medios probatorios o por carecer de algún requisito que la ley exija de las pruebas para que generen la convicción necesaria en los jueces.

Sin embargo, también vale notar que los correos electrónicos no existen exclusivamente en un mundo virtual, sino que los tribunales les reconocen una relevancia jurídica palpable, pues en sí son hechos comunicacionales que pueden por sí, independientemente de su contenido, afectar las relaciones jurídicas de las personas.

\section{Conclusión}

En base al desarrollo efectuado a lo largo de la investigación, consideramos estar en condiciones de arribar a las siguientes conclusiones: Se ha analizado la cuestión de la fuerza probatoria de los correos electrónicos desde diversas perspectivas. Primeramente se conceptualizó y describió el objeto con el fin de aproximar al lector los elementos que lo distinguen de otros medios de prueba similares.

Esa definición lleva a entender que los e-mail se manifiestan como una herramienta más de la vida jurídica de la sociedad, que si bien es novedosa, no presenta en abstracto mayores dificultades para ser aceptada como hábil para las comunicaciones de las relaciones negóciales.

De hecho en gran medida son convenientes, pues sus caracteres de ubicuo y asíncrono, unidos a que son electrónicos y digitales, permiten una velocidad y facilidad nunca antes vista para las tratativas propias de todo acto jurídico.

Sin embargo, la primera percepción, abstracta, no advierte las posibles dificultades que presenta la herramienta en su aplicación práctica. De allí que se expuso con mayor detalle las distintas vulnerabilidades que puede presentar para la protección y afirmación de los valores jurídicos de seguridad y celeridad de los actos jurídicos.

Para ello se explicaron en mayor detalle los requisitos que hacen a todos los actos jurídicos, para que en el contraste con los analizados en particular, se pongan de manifiesto las potenciales asperezas en su funcionamiento. 


\section{LA EFICACIA DEL CORREO ELECTRÓNICO COMO MEDIO DE CONFIRMACIÓN EN EL PROCESO CIVIL Y COMERCIAL}

Esas asperezas son las que justifican la desconfianza del sistema jurídico en la asimilación de las TIC en general, y de los correos electrónicos en particular, a los mecanismos legales. Sin embargo, el exceso en la precaución también es peligroso, por lo que se han hecho avances al respecto en las últimas décadas, abriendo un gran abanico de posibilidades al mundo jurídico.

En ese abanico, la plasticidad y variabilidad de los objetos digitales se presenta como una gran fuente de potenciales expresiones humanas, específicamente a los e-mails y su faz legal, se manifiesta en las múltiples formas que pueden adoptar estos documentos (instrumentos, registros, monumentos). Lo que también genera modos más ricos de almacenamiento de la información jurídicamente relevante.

Se ha visto también, que los documentos electrónicos en general son capaces de poseer los requisitos de inalterabilidad, autenticidad, y durabilidad de todo documento, aunque no sin peculiaridades que han dado origen a diversas formas de proteger y asegurar esos elementos.

La seguridad necesaria ha avanzado enormemente, lo que favorece la integración de las herramientas informáticas al escenario jurídico, permitiendo la creación de mecanismos de protección que aseguran la tranquilidad de los negocios.

Gracias a esos sistemas criptográficos se ha podido construir la infraestructura de clave pública PKI, que a su vez ha permitido la equiparación final de los documentos electrónicos y las firmas digital y electrónica a los tradicionales. Así, se completa la integración de ambos mundos, que si bien aún es inmadura ya puede avanzar con pie firme.

Comprendido entonces el objeto, el contexto en el que se desarrolla y el alcance que posee en el mundo jurídico, es que se ingresó al análisis de su actuación más práctica, su validez como medio de confirmación en los juicios.

Desde una perspectiva general, se analizaron las dimensiones de la prueba en general, el objeto, el tema, la fuente, la incumbencia, y los medios de confirmación. Y cómo esas dimensiones se conectan con los e-mail en particular.

Luego se analizaron los requisitos de existencia, validez y eficacia de los documentos con medios probatorios. 


\section{LA EFICACIA DEL CORREO ELECTRÓNICO COMO MEDIO DE CONFIRMACIÓN EN EL PROCESO CIVIL Y COMERCIAL}

Por último se analizó como todos aquellos conceptos se cristalizan en casos particulares, y como diversas situaciones pueden hacer variar la fuerza conviccional que poseen los correos electrónicos. Esos casos también demostraron que los correos en sí mismos pueden erigirse como tema de confirmación, por lo que no sólo pueden demostrar lo que ha sido codificado en su contenido, sino que también pueden servir como prueba de los actos comunicacionales que facilitan.

Queda decir finalmente cómo es que se puede prever la fuerza conviccional de los correos electrónicos en los procesos. Esta es una tarea sumamente compleja y difícilmente se pueda predicar con absoluta certeza sobre la totalidad de las posibles manifestaciones que ellos pueden tener.

Sin embargo, siguiendo el esquema que se presentó al hablar de los medios de confirmación se puede aventurar que los e-mail no son medios de comprobación, pues no poseen, en ninguna de sus formas, la posibilidad de demostrar verdades científicas. Puede demostrarse, científicamente, la verdad de su existencia y de su autenticidad, pero en ese caso el medio de prueba no será el correo en sí mismo, sino el peritaje que se actuará sobre él.

Tampoco se erigen, en general, en medios de mostración. Esto es así pues los documentos, en general, sólo almacenan información relativa a un hecho u objeto, y no pueden contenerlo propiamente. Cabe hacer una aclaración, y es que cuando el hecho a confirmar sea la existencia misma de los correos electrónicos, pueden estos ser exhibidos, sin embargo en este caso la exhibición misma es el medio de confirmación y el e-mail se convierte en tema de confirmación.

Queda entonces por distinguir si son medios de acreditación o de mera convicción. Respecto de la posibilidad de que sean exclusivamente medio de convicción, se debe estar por la negativa, los correos electrónicos existen con un nivel de certeza lo suficientemente elevado, y las posibilidades de modificación de los mismos son lo suficientemente escasas, como para producir más que sólo un indicio subjetivo en la mente del juzgador. Aunque esto no implica que no puedan lograr ese convencimiento y aún más, dado el caso.

Si bien se podría imaginar la posibilidad de que exista un correo electrónico, de tan dudoso origen, que no permita más que una fuerza de convicción indiciaria, tal circunstancia 


\section{LA EFICACIA DEL CORREO ELECTRÓNICO COMO MEDIO DE CONFIRMACIÓN EN EL PROCESO CIVIL Y COMERCIAL}

deberá estar claramente fundada y justificada por las reglas de la sana crítica racional, pues como se explico oportunamente, los mecanismos de seguridad y conservación de la información de los documentos electrónicos son suficientemente sofisticados como para asegurar un nivel de confirmación elevado.

Queda entonces preguntarse si de hecho los correos electrónicos se erigen en medios de acreditación. Es posible afirmar con tranquilidad esa proposición, pues se trata de documentos, electrónicos pero sin duda documentos. Que a su vez pueden participar de todo el rango de fuerza conviccional que otros documentos que sirven de acreditación. Pues, dados los requisitos exigidos por la ley, tales como la firma digital, pueden ofrecer fe de su origen y contenido, o pueden simplemente ser documentos privados que requieren de otros medios de confirmación coadyuvantes para lograr la entera certeza de lo que se busca probar.

Sin embargo, esa relatividad no es óbice para el rango que disfrutan, sino por el contrario, simplemente atestigua la diversidad y amplitud de formas y manifestaciones que los ciudadanos les hacen adoptar, y la versatilidad que ofrecen para la realización de tantos y tan diversos negocios jurídicos. 


\section{LA EFICACIA DEL CORREO ELECTRÓNICO COMO MEDIO DE CONFIRMACIÓN EN EL PROCESO CIVIL Y COMERCIAL}

\section{Bibliografía}

Altmark, D. R., \& Molina Quiroga, E. (2012). Tratado de Derecho Informático (Vol. I). Buenos Aires: La Ley.

Alvarado Velloso, A., \& Gonzalez Castro, M. A. (2012). Lecciones de Derecho Procesal Civil. Rosario: Fundación para el Desarrollo de las Ciencias Jurídicas.

Ferreyra de de la Rúa, A., \& Gonzáles de la Vega de Opl, C. (2002). Código Procesal Civil

y Comercial de la Provincia de Córdoba, Comentado y Concordado con los Códigos de la Nación y Provinciales (Vol. 2). Buenos Aires: La Ley.

Internet Engineering Task Force. (Octubre de 2008). Internet Engineering Task Force. (P. W. Resnick, Ed.) Recuperado el 13 de Julio de 2015, de RFC 5322 - Internet Message Format: https://tools.ietf.org/html/rfc5322

Leiner, B. M., Cerf, V. G., Clark, D. D., Kahn, R. E., Kleinrock, L., Lynch, D. C., . . . Wolff, S. (s.f.). Internet Society. Recuperado el 12 de Julio de 2015, de Breve Historia de Internet: http://www.internetsociety.org/es/breve-historia-de-internet

Luz Clara, B. (2006). Ley de Firma digital comentada. Buenos Aires: Nova Tesis.

Peter, I. (2004). NetHistory. Recuperado el 12 de Julio de 2015, de The history of email: http://www.nethistory.info/History\%20of\%20the\%20Internet/email.html

Rodriguez Saiach, V. M. (2014). Prueba y Carga de la Prueba en Materia Informática. Buenos Aires: Gowa.

Rodriguez Silvda, E. (2003). Revista Chilena de Derecho Informático. Recuperado el 13 de Julio de 2015, de El Correo Electrónico: http://www.derechoinformatico.uchile.cl/index.php/RCHDI/article/view/10668/114 14

The Radicati Group Inc. (2015). The Radicati Group. Recuperado el 12 de Julio de 2015, de Email Statistics Report, 2015-2019: http://www.radicati.com/wp/wpcontent/uploads/2015/02/Email-Statistics-Report-2015-2019-ExecutiveSummary.pdf 